\title{
Some Interesting Features of Non-Covalent Interactions ${ }^{\dagger}$
}

\author{
Ana Martín-Sómer, ${ }^{\mathrm{a}}$ M. Merced Montero-Campillo, ${ }^{\mathrm{a}}$ Otilia Mó, ${ }^{\mathrm{a}}$ \\ Manuel Yáñez, ${ }^{\mathrm{a}, *}$ Ibon Alkorta, ${ }^{\mathrm{b}}$ and José Elguero ${ }^{\mathrm{b}}$ \\ ${ }^{a}$ Departamento de Química, Facultad de Ciencias, Módulo 13. Universidad Autónoma de Madrid, \\ Campus de Excelencia UAM-CSIC. Cantoblanco, E-28049 Madrid, Spain \\ ' Instituto de Química Médica, CSIC, Juan de la Cierva, 3, E-28006 Madrid, Spain
}

RECEIVED APRIL 4, 2014; REVISED JUNE 3, 2014; ACCEPTED JUNE 6, 2014

\begin{abstract}
Interactions between closed-shell systems exhibit some common features, four of which are particularly strong for beryllium bonds: geometrical distortion, cooperativity, changes in intrinsic reactivity and changes in the magnetic properties of the interacting subunits, which reflect the perturbations of their electron densities through polarization effects. Structural changes lead to interaction energies that can only be adequately accounted for when the effects of the distortion on the intrinsic reactivity of the system, and not only its deformation energy, are taken into consideration. Self-assembling of ditopic systems may lead to $n$-mers stabilized by strong cooperative effects. Chemical shifts and coupling constants also reflect the perturbations of the electron density and accordingly cooperative effects. These four features are common to any interaction involving two closed-shell systems, one acting as Lewis acid and the other as Lewis base, and the only difference between the nature of the interactions is quantitative.
\end{abstract}

Keywords: non-covalent interactions, beryllium bonds, cooperativity, metallocycles, deformation, acidity enhancement, self-assembling

\section{INTRODUCTION}

Chemical bonding is at the very heart of chemistry and is probably one of its most fundamental concepts. However, there is not a clear-cut definition of what a chemical bond is and this is particularly so when we refer to "non-covalent interactions". It is of common use to denote under this general name all weak interactions, typically between closed-shell systems with no electron sharing between the interacting subunits. There is however a great variety of non-covalent interactions attending both to their energy and to their nature, and some of them are almost as strong as conventional covalent linkages. Non-covalent interactions have received a great deal of attention already at the end of the XIX century after the seminal work of J. D. Van der Waals, ${ }^{1}$ followed later on by the contributions of P. Debye on polarization effects, ${ }^{2} \mathrm{~F}$. London on dispersion forces, ${ }^{3,4}$ and J. E. Lennard-Jones on the development of a still used potential. ${ }^{5}$

The continued interest on non-covalent interactions along the whole XX century and the beginning of the XXI is not at all surprising taking into account that they are responsible for the organization of practically all molecular assemblies, either natural like DNA, or artificial like the so-called metal-organic-frameworks (MOFs), or "soft matter", term commonly employed to describe materials that are held together by noncovalent interactions involving energies of the order of the thermal energy, $k \mathrm{~T}$. Among the different noncovalent interactions, the so called hydrogen bonds are the most studied since the publication of Linus Pauling's book on chemical bonding, ${ }^{6}$ in which he credited T. S. Moore and T. F. Winmill as the first ones mentioning this kind of linkages in their study of amines in aqueous solution. ${ }^{7}$ The discovering of hydrogen bonds was followed by a significant number of other closed-shell interactions as dihydrogen bonds, ${ }^{8}$ halogen bonds,,${ }^{9,10}$ beryllium bonds, ${ }^{11}$ pnicogen bonds, ${ }^{12,13}$ and others, some of which were characterized for the first time in the present century. ${ }^{11}$

In most of these non-covalent interactions, probably with the only exception of van der Waals clusters, electrostatic and polarization interactions are important contributors to their stability. In some cases polarization effects are so strong that actually a net charge transfer between the interacting sub-units takes place. ${ }^{14}$ This is the case in beryllium bonds, where a Lewis base interacts

\footnotetext{
$\dagger$ Dedicated to Dr. Mirjana Eckert-Maksić on the occasion of her $70^{\text {th }}$ birthday.

* Author to whom correspondence should be addressed. (E-mail: manuel.yanez@uam.es)
} 
with a beryllium derivative acting as Lewis acid, and where a significant charge transfer from the Lewis base towards the empty $p$ orbitals of $\mathrm{Be}$, as well as into the $\sigma_{\mathrm{BeX}} *$ antibonding orbitals of the $\mathrm{BeX}_{2}$ compound takes place. ${ }^{11}$ A similar process, although in general much weaker, can be also identified in conventional $\mathrm{X}-\mathrm{H} \cdots \mathrm{Y}$ hydrogen bonds, which usually involves a small charge transfer from the lone pairs of the HB acceptor $\mathrm{Y}$, into the $\sigma_{\mathrm{XH}}{ }^{*}$ antibonding orbitals of the HB donor. ${ }^{15}$ These charge density fluctuations associated with the formation of these, usually weak, linkages are behind the cooperative or non-pairwise effects. It is well known for instance, that the HBs in water trimer are stronger than the HB that holds together the water dimer, due to the fact that the presence of more than one of these weak interactions within the same system, results in a reinforcement (or weakening) of each of the individual interactions, what is known as cooperativity (or anticooperativity). But this is not the only effect of the charge density redistribution undergone by the monomers which participate in the interaction. One of the signatures of these linkers is the deformation undergone by the Lewis acid and/or the Lewis base. This feature has been recognized long time ago, and it is well established that the energy used in the deformation of the interacting monomers is a fundamental component to get physically meaningful interaction energies. ${ }^{16}$ Nevertheless, recently it was proved that to account for the relative stabilities of the complexes formed through these interactions is not enough to include the deformation energy but to take into account the changes produced in the intrinsic reactivity of the monomers, as a consequence of the aforementioned deformations. ${ }^{17,18}$ Depending on the magnitude of the polarization from the Lewis base to the Lewis acid, the intrinsic reactivity of both moieties can dramatically change.

The aim of this feature article is to offer a general perspective on these basic and common characteristics of closed-shell interactions, namely the role of the deformation, the cooperative effects, and the effects on the intrinsic reactivity of the interacting sub-units, paying also attention to these phenomena when associated with the presence of recently described beryllium bonds.

\section{METHODOLOGY}

In some manner the theoretical treatment of most noncovalent interactions is a challenge because it is necessary to reproduce very small interaction energies generally as the difference between two big numbers, the energy of the complex and the sum of the energies of the two interacting subunits. This can be critical when dealing with van der Waals complexes, where the larger component of the interaction energy comes from dispersion, which is a second order correction which cannot be described neither at the HF or at the DFT level; but even in other cases in which the interaction includes a good amount of electrostatic, polarization or even covalent effects, the accurate description of the corresponding closed-shell interaction is not trivial. Correlation effects are very important and the basis set has to be flexible enough to well describe the small electron density within the region of the interaction, so in general the inclusion of diffuse components becomes mandatory. In the cases to be described along this paper, different theoretical schemes have been employed, but even when the results were obtained through the use of DFT approaches, the methods were previously assessed using ab initio $\operatorname{CCSD}(\mathrm{T})$ calculations as a reference.

The bonding was usually analyzed by means of the Quantum Theory of Atoms in Molecules (QTAIM) ${ }^{19}$ or the electron localization function (ELF) theory. ${ }^{20,21}$ The first one is based on a topological analysis of the electron density, which permits to build up the so called molecular graphs as the ensemble of the critical points of the electron density: maxima associated with the position of the nuclei, first order saddle points usually called bond critical points (BCPs), second order saddle points or ring critical points (RCPs) or minima which correspond to cage critical points (CCP). The zero flux lines containing a BCP and connecting the different maxima complete the molecular graph. In general there is a clear correlation between the density at the BCPs and the strength of the linkage.

An alternative view can be obtained through the use of ELF, which permits to divide the physical space in basins associated with the probability of locating an electron pair. These basins may be monosynaptic, if they depend on the orbitals centered on a single atom, core or electron-pairs, or disynaptic when the basin includes the participation of orbitals from two bonded atoms, so the basin is occupied by a bonding pair. The populations of these basins also permit to have useful information of the bonding and its strength.

\section{THE ROLE OF THE DEFORMATION}

\section{Strong Deformation of the Lewis Acid}

Several characteristics of the complexes involving borane and some of its derivatives, in particular those in which the hydrogen atoms have been substituted by halogens, have received a great deal of attention; but in this section we will focus our interest on questions related with the deformation of borane and borane derivatives when attached to a Lewis base. It has been known for a long time that these derivatives depart significantly from planarity when they form complexes with typical bases. ${ }^{16}$ It is also known that the amount of energy to be paid strongly depends on the nature of the atoms attached 

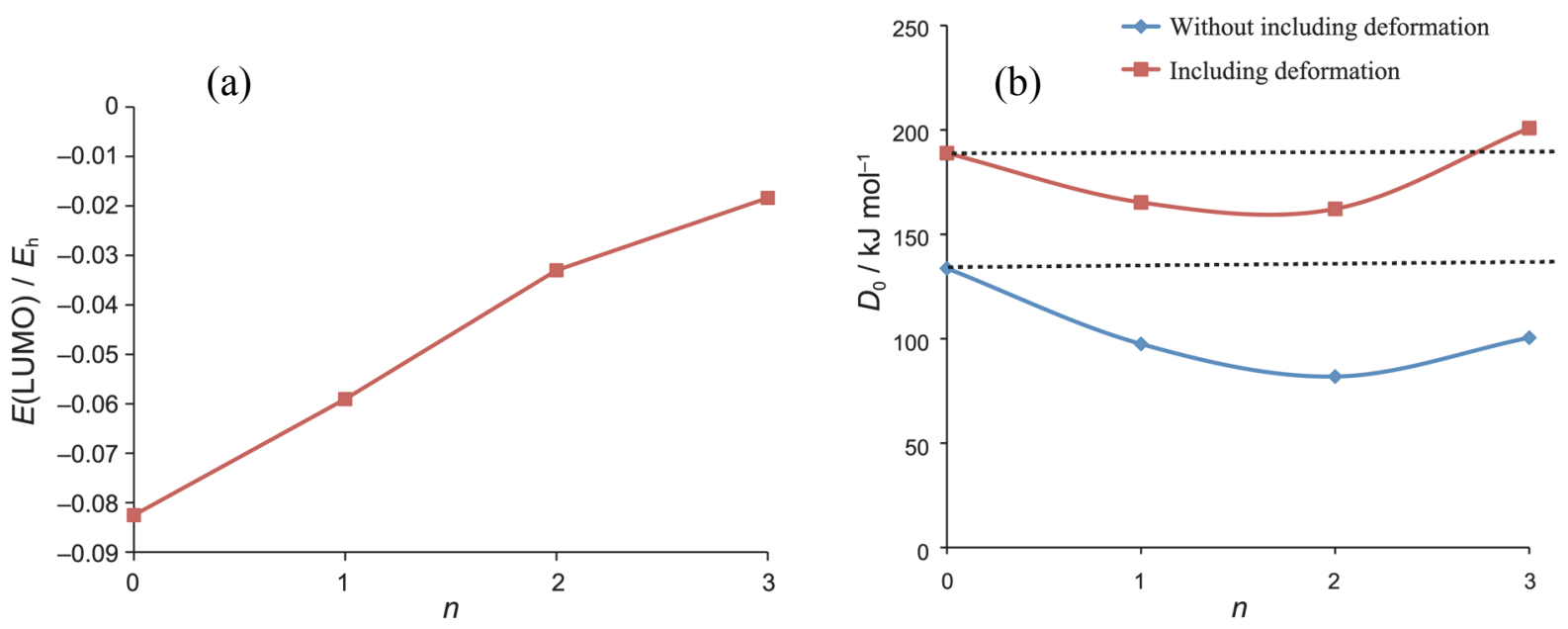

Figure 1. Variation of the energy of the LUMO of the $\mathrm{BH}_{3-n} \mathrm{~F}_{n}$ compounds, in their equilibrium conformation, as a function of the the number ( $n$ ) of fluorine substituents (a). Variation of the dissociation energy of the $\mathrm{NH}_{3}: \mathrm{BH}_{3}-n \mathrm{~F}_{n}$ clusters as a function of the number $(n)$ of fluorine substituents, including and without including the energy term associated with the deformation of the Lewis acid and the Lewis base (b). The latter is almost negligible as compared with the former.

to $\mathrm{B}$, so it is significantly larger for $\mathrm{BF}_{3}$ than for $\mathrm{BH}_{3} .^{22,23}$ The main consequence is that the conventional dissociation energies, defined as the energy difference between the complex and that of the isolated Lewis base and Lewis acid in their equilibrium conformation, is not a good measure of the strength of the interaction because this dissociation energy is the smaller, the greater the deformation of the interacting subunits. ${ }^{17}$ This actually explains why the dissociation energy of $\mathrm{BH}_{3}$ complexes is greater than that of $\mathrm{BF}_{3}$ complexes, even though $\mathrm{BF}_{3}$ should be a stronger acid than $\mathrm{BH}_{3}$.

It is important to emphasize however, that the inclusion of the deformation energy does not always solve the possible inconsistencies. A paradigmatic example is that of the complexes between ammonia and $\mathrm{BF}_{3}$ and $\mathrm{BCl}_{3}$, where the dissociation energy of the complex into $\mathrm{NH}_{3}+\mathrm{BX}_{3}(\mathrm{X}=\mathrm{F}, \mathrm{Cl})$ is larger for the $\mathrm{BCl}_{3}$ complex than for the $\mathrm{BF}_{3} .{ }^{24}$ Why $\mathrm{BCl}_{3}$ behaves apparently as a stronger Lewis acid than $\mathrm{BF}_{3}$ is not a trivial question, that certainly cannot be explained in terms of the deformation energies, because the deformation energies of $\mathrm{BF}_{3}$ and $\mathrm{BCl}_{3}$ are practically identical. The origin of the larger acidity of $\mathrm{BCl}_{3}$ can be traced using the frontier orbital energy, which shows that the LUMO of $\mathrm{BCl}_{3}$ lies lower in energy than that of $\mathrm{BF}_{3}$, and therefore one should expect the former to be a better electron acceptor, and as a consequence a better Lewis acid than the latter. ${ }^{24}$

However, even this model may be incomplete if the effect of the deformations on the properties of the interacting units is not taken into account. Naively, one would expect the Lewis acidity to increase by successive substitution by $\mathrm{F}$ atoms as $\mathrm{BH}_{3}<\mathrm{BH}_{2} \mathrm{~F}<\mathrm{BHF}_{2}<$ $\mathrm{BF}_{3}$. Indeed, the energy of the LUMO increases practically linearly with the increase in the number of fluorine substituents as shown in Figure 1a. However, high-level $\mathrm{ab}$ initio calculations ${ }^{17}$ show the variation of the dissociation energy of $\mathrm{NH}_{3}: \mathrm{BH}_{3-n} \mathrm{~F}_{n}$ complexes into $\mathrm{NH}_{3}+$ $\mathrm{BH}_{3-n} \mathrm{~F}_{n}$ is far from being linear, since, as shown in Figure $1 \mathrm{~b}, \mathrm{BH}_{2} \mathrm{~F}, \mathrm{BHF}_{2}$ and $\mathrm{BF}_{3}$ are found to be weaker Lewis acids than borane, so that the curve presents a minimum for $\mathrm{BHF}_{2}$.

The apparently anomaly is only partially solved when the energy contributions of the deformation are included in the model, and $\mathrm{BF}_{3}$ is found to be, as expected, a stronger Lewis acid than $\mathrm{BH}_{3}$. Quite surprisingly however, $\mathrm{BH}_{2} \mathrm{~F}$ and $\mathrm{BHF}_{2}$ are still predicted to be weaker Lewis acids than the unsubstituted parent compound! The origin of this unexpected behavior is closely related to the deformation, although not only to the energy involved in such a deformation, that is included in the red curve of Figure 1b, but also to its effects on the electron acceptor properties of the Lewis acid. Indeed, the $\mathrm{BH}_{3-n} \mathrm{~F}_{n}$ compounds are planar in their equilibrium conformation, so their LUMO is a pure $2 p$ orbital centered on the boron atom. However, when the system becomes pyramidal in the complex, the symmetry changes and the $2 p$ orbital can now mix with the $2 s$ orbital, so that the LUMO orbital of the distorted $\mathrm{BH}_{3-n} \mathrm{~F}_{n}$ compound is a $s p$ hybrid, whose energy depends on how large the s participation is (See Figure 2a). The main consequence is that the energy of the LUMO varies with the number of the F substituents as shown in Figure 2b.

Hence, in contrast with what would be expected, the energy of the LUMO does not increase linearly with the number of electronegative substituents attached to the boron atom, and rather the energy goes through a maximum at $\mathrm{BHF}_{2}$. Not surprisingly then, the interaction 
(a)

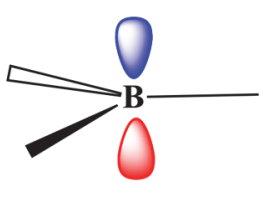

Isolated

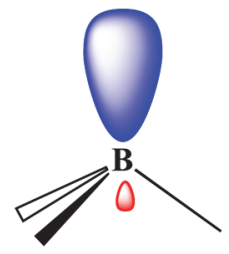

In the complex

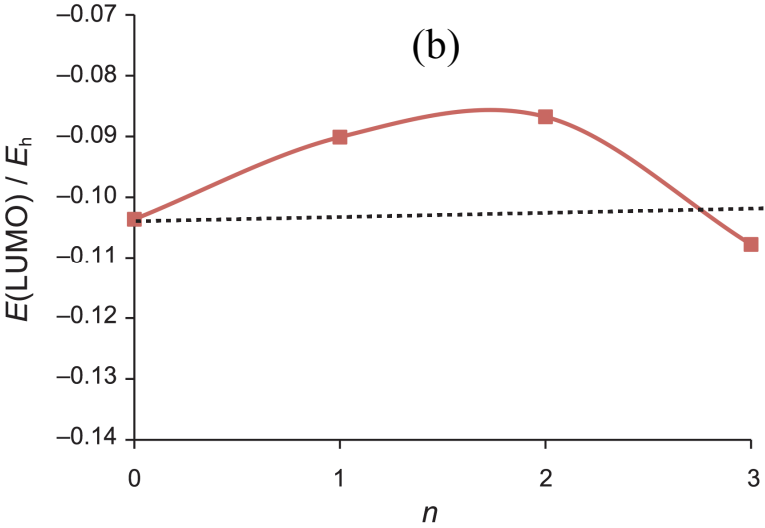

Figure 2. Schematic representation of the LUMO for $\mathrm{BH}_{3-n} \mathrm{~F}_{n}$ compounds in their equilibrium (isolated) conformation and in the distorted conformation they adopt in $\mathrm{NH}_{3}: \mathrm{BH}_{3-n} \mathrm{~F}_{n}$ complexes (a). Variation of the energy of the LUMO as a function of the number of fluorine substituents for $\mathrm{BH}_{3-n} \mathrm{~F}_{n}$ compounds in the distorted geometry they adopt in $\mathrm{NH}_{3}: \mathrm{BH}_{3-n} \mathrm{~F}_{n}$ complexes (b).

energy between this compound and ammonia, as illustrated in Figure 1b is the lowest of the four derivatives, followed by $\mathrm{BH}_{2} \mathrm{~F}$. Also consistently with the calculated interaction energies including the deformation contributions, $\mathrm{BF}_{3}$ should be a stronger Lewis acid than $\mathrm{BH}_{3}$, since its LUMO is the lowest one of the whole series.

This situation is not only found in boron complexes, but is also reproduced when dealing with beryllium bonds. ${ }^{25}$ Again surprisingly in the $\mathrm{NH}_{3}: \mathrm{BeH}_{2-n} \mathrm{~F}_{n}$ complexes the interaction energy does not increase steadily with the number of fluorine substituents (See Figure 3a) because the value calculated for the $\mathrm{NH}_{3}$ :BeHF complex is smaller than the one calculated for the unsubstituted parent compound. If the LUMO of the three Lewis acids, namely $\mathrm{BeH}_{2}, \mathrm{BeHF}$ and $\mathrm{BeF}_{2}$ in their equilibrium conformations is taken as a measure of their intrinsic capacity as electron acceptors (See Figure 3b) one should conclude that the Lewis acidity of $\mathrm{BeH}_{2}$ and $\mathrm{BeF}_{2}$ should be practically equal, whereas that of $\mathrm{BeHF}$ should be much smaller than the other two, what is in clear contrast with the calculated dissociation energies. Both variations are reconciled however if we consider the variation of the LUMO of the distorted Lewis acids, rather than that at equilibrium. As shown in Figure 3b, for the beryllium derivatives with the geometry they have in the complexes with ammonia, BeHF is predicted to exhibit an acidity similar to the unsubstituted parent compound, whereas $\mathrm{BeF}_{2}$ should be a much stronger electron acceptor. ${ }^{25}$

\section{Strong Deformation of the Lewis Base}

In the examples described in the previous section, although both the Lewis acid and the Lewis base undergo
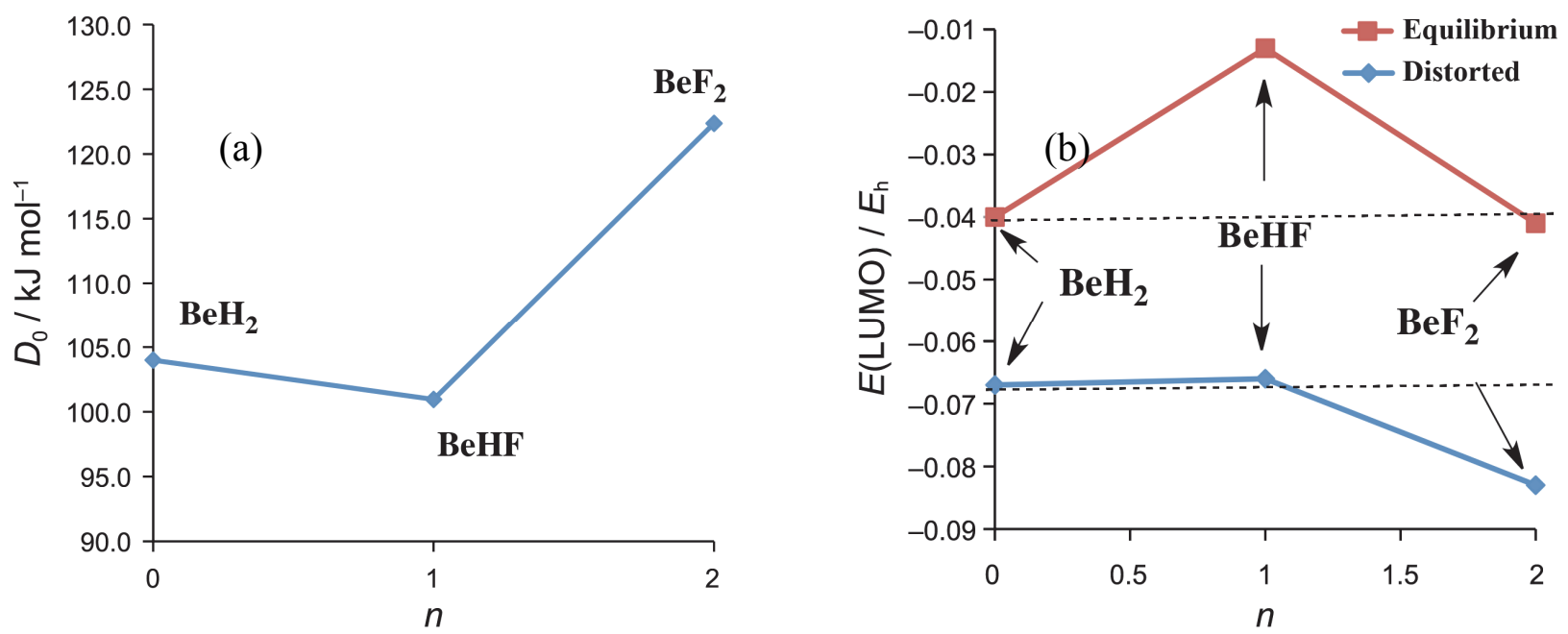

Figure 3. Variation of the dissociation energy of the $\mathrm{NH}_{3}: \mathrm{BeH}_{2-n} \mathrm{~F}_{n}$ clusters as a function of the number $(n)$ of fluorine substituents (a). Variation of the energy of the LUMO for the three Lewis acids at their equilibrium conformation and at the distorted conformation they have in the $\mathrm{NH}_{3}: \mathrm{BeH}_{2-n} \mathrm{~F}_{n}$ complexes (b). 


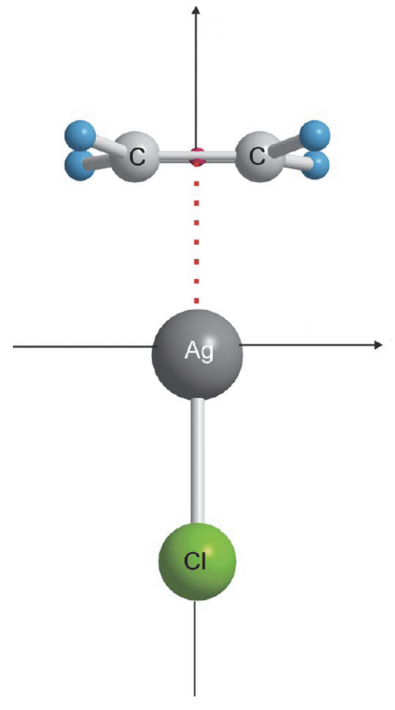

Figure 4. Experimental MW structure of complex $\mathrm{C}_{2} \mathrm{H}_{4} \cdots \mathrm{Ag}-\mathrm{Cl}$.

a certain deformation, these effects were more evident in the former. However, this is not always so and in other systems is the deformation of the Lewis base, as we shall illustrate in this section, the one that dominates.

In 2011, Stephens, Tew, Mikhailov, Walker and Legon described, for the first time, the structure in the gas-phase of the transition-metal olefin complex $\mathrm{C}_{2} \mathrm{H}_{4} \cdots \mathrm{Ag}-\mathrm{Cl}^{26}$ The compound was synthesized in a
pulsed-jet-Fourier-transform microwave (MW) spectrometer as represented in Figure 4.

The authors reported unpublished results indicating that the complex $\mathrm{C}_{2} \mathrm{H}_{4} \cdots \mathrm{Cu}-\mathrm{Cl}$ is very similar. By combining experimental results and fc-CCSD(T)/ccpVQZ theoretical calculations, they reached the following conclusions: the $\mathrm{C}-\mathrm{C}$ bond of ethylene (ethene) lengthens on formation of the complex and simultaneously the ethylene molecule undergoes a small angular distortion. The distortion is such that the four $\mathrm{H}$ atoms move in a direction away from $\mathrm{Ag}$ but remain coplanar. The two $\mathrm{C}$ atoms are no longer contained in this plane, however.

Shortly after, we studied ${ }^{18}$ the copper complex and, using the facility of theoretical methods [MP2 and $\operatorname{CCSD}(\mathrm{T})$ computational levels] to explore large zones around a problem, we extended the study of ethylene to acetylene (ethyne) and to their fluoro derivatives (Figure 5) by analogy with the results reported in previous section.

Several conclusions were obtained, such as the metallocyclic nature of these three-membered $\mathrm{C}-\mathrm{C}-\mathrm{Cu}$ rings, with interaction energies between $\mathrm{CuF}$ and $\mathrm{CC}$ double and triple bonds close to those of conventional covalent ones. ${ }^{18}$ Though, for the purpose of this review, we will focus on the effect of fluorine substitution on the strength of the interaction of $\mathrm{CuF}$ with the organic part, because this is related to the important question of the deformation of the base.
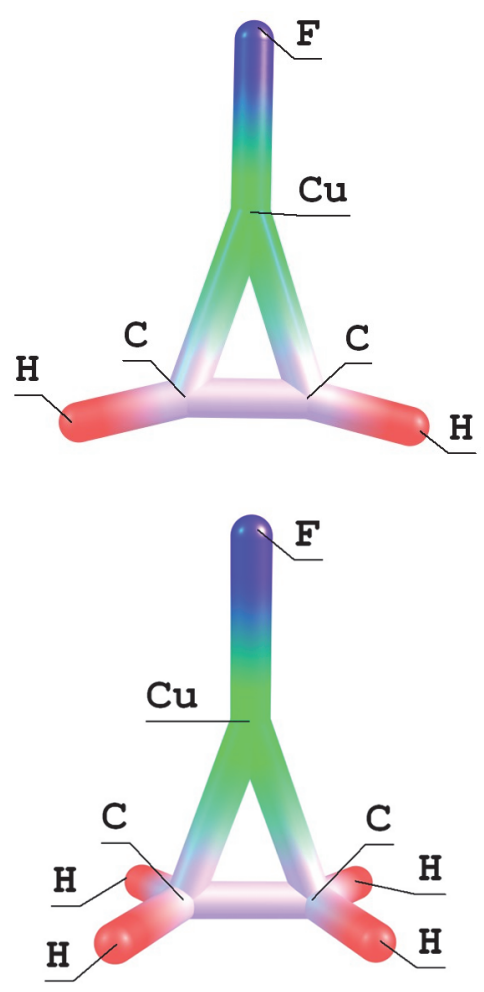
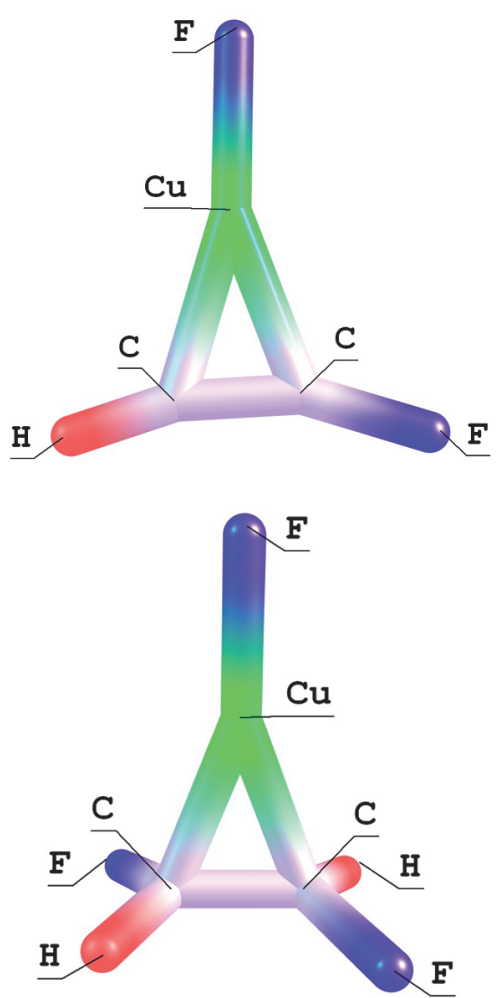
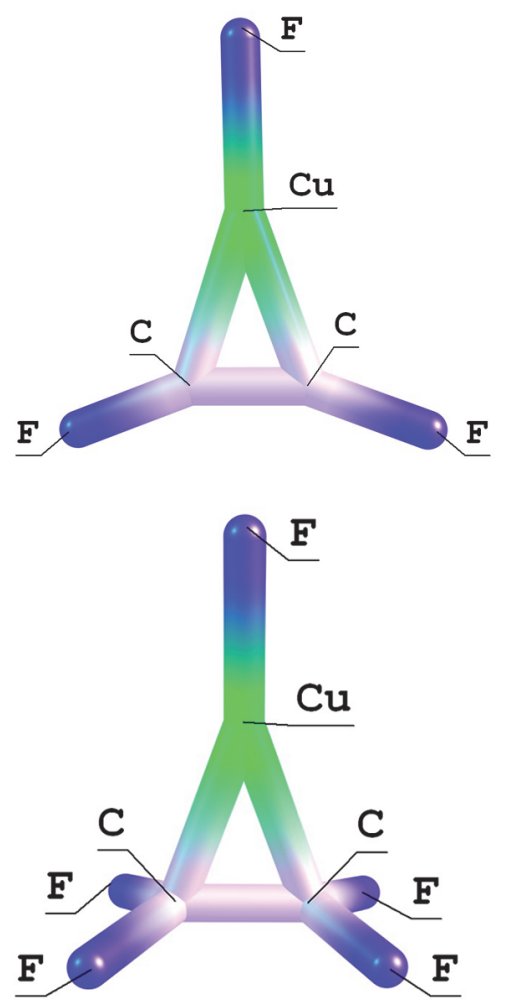

Figure 5. Complexes between $\mathrm{CuF}$ and acetylene, fluoroacetylenes, ethylene and fluoroethylene derivatives. 
The increase of the interaction energies with the number of fluorine substituents is only observed in the acetylene series. An analysis of the bonding in both series of complexes indicates a similar nature, that fits very well the Dewar-Chatt-Duncanson model, and therefore, the reason for this unexpected behavior could only be associated once more with the effects triggered by the distortion of the system, quantitatively different for acetylene than for ethylene derivatives and much larger for the F-substituted derivatives than for the unsubstituted parent compounds.

There are two alternative ways of partitioning the dissociation energy $\left(D_{\mathrm{e}}\right)$ into interaction and deformation energies, the classical one, in which the deformation energy, $E_{\mathrm{def}}$, is the energy needed to distort both monomers from their equilibrium conformation to the one they have in the complex or an alternative one in which $D_{\mathrm{e}}$ is partitioned into the energy needed to deform the complex, $E_{\text {def }} C$, plus the interaction energy between both undistorted monomers, $E_{\mathrm{int}} D$. $E_{\mathrm{int}} D$ is then calculated maintaining fixed the structure of the monomers in their equilibrium conformation, whereas only the distance between the $\mathrm{CuF}$ molecule and the unsaturated compound and their relative orientation were allowed to change (See Figure 6).

The surprising finding as illustrated in Figure 7 is that whereas the $E_{\text {int }} D$, in which the distortion of the monomers are not allowed, follows the same trend for both families of complexes upon $\mathrm{F}$ substitution (red arrows), this is not the case for $E_{\text {int }}$ which increases for the ethylene series (blue arrow) but decreases for the acetylene one (green arrow).

A perusal of the values in Figure 7 clearly shows that this opposite behavior has its origin on the much larger deformation energy of the complex involving $\mathrm{FC} \equiv \mathrm{CF}\left(52.8 \mathrm{~kJ} \cdot \mathrm{mol}^{-1}\right)$ than of the complex involving $\mathrm{HFC}=\mathrm{CHF}\left(21.6 \mathrm{~kJ} \cdot \mathrm{mol}^{-1}\right)$. The origin of this significant difference can be understood by looking at the

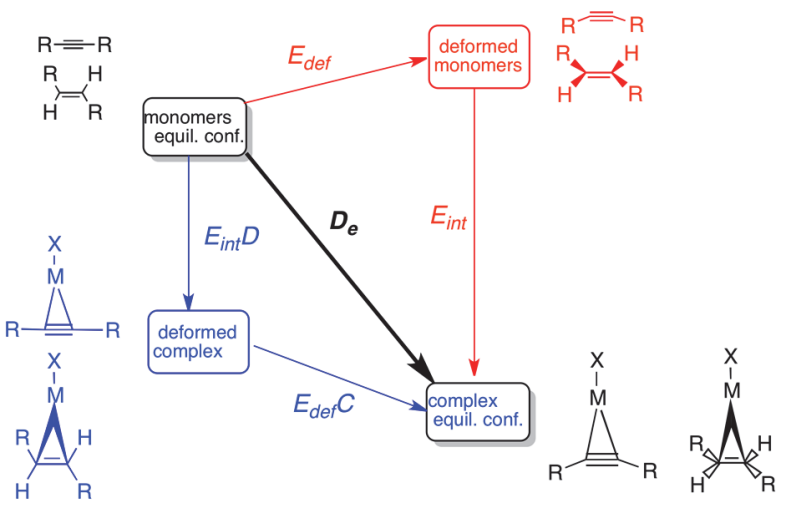

Figure 6. Thermodynamic cycle relating $D_{\mathrm{e}}$ with the deformation energy of the interacting monomers, $E_{\text {def, }}$ and the deformation energy of the complex, $E_{\mathrm{def}} C . E_{\mathrm{int}}$ is the interaction energy.
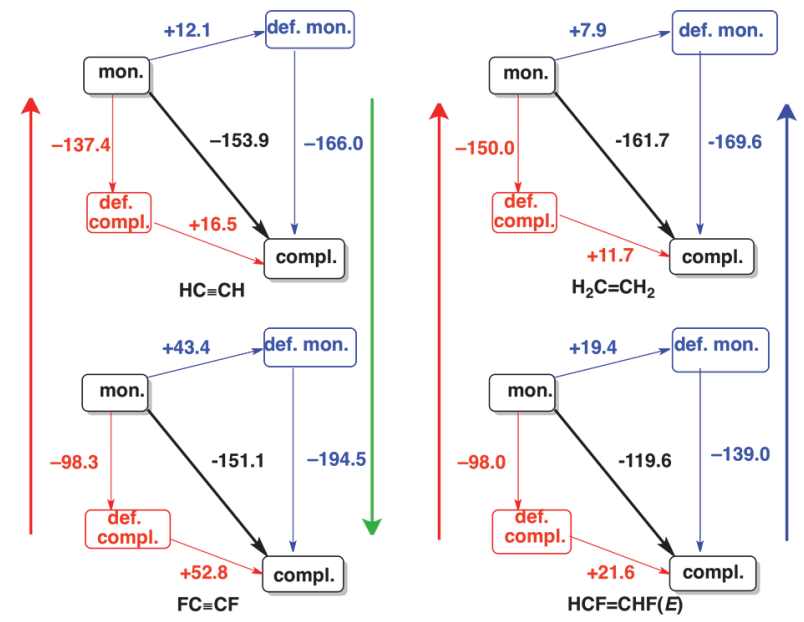

Figure 7. Thermodynamic cycles showing the values of $D_{\mathrm{e}}$, $E_{\text {int }}, E_{\text {int }} D, E_{\text {def }}$ and $E_{\text {def }} C$ for the complexes formed by the interaction of acetylene, ethylene and its fluoro disubstituted derivatives with $\mathrm{CuF}$.

variation of the interaction energy as a function of the deformation, as measured by the angle $\alpha$ defined in Figure 8 .

It can be observed that the two parent compounds exhibit a rather similar behavior upon deformation (curves red and blue) since the curves have rather similar slopes. However, the F disubstitution leads to a more significant decrease of the interaction energy with the deformation for the FCCF (yellow curve) than for the HFCCFH compound (purple curve). Very importantly, at the equilibrium conformation the potential energy

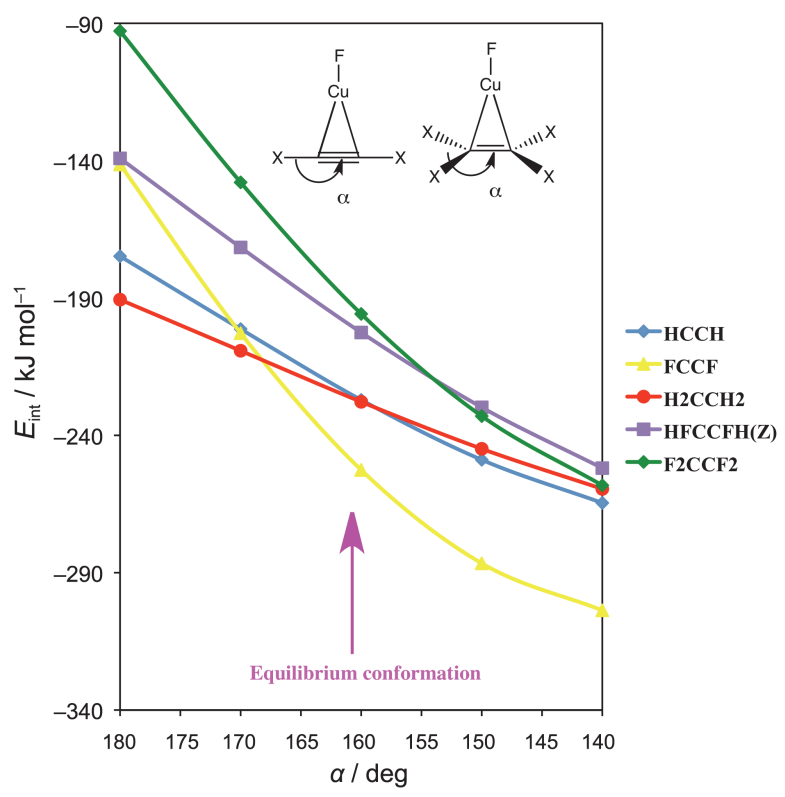

Figure 8. Variation of the interaction energy between $\mathrm{CuF}$ and ethylenic and acetylenic derivatives as a function of the deformation of the unsaturated organic compound. 
curve for the FCCF complex has already crossed (around $170^{\circ}$ ) the one corresponding to the unsubstituted $\mathrm{HCCH}$ parent compound, whereas this crossing did not take place yet for the HFCCFH complex, explaining why for the acetylenic series the interaction energy of the difluoro derivative is greater, in absolute value, than that of the parent compound, whereas this is not the case for the difluoro ethylenic derivative. Still, we need to understand why the slope of the yellow curve is much larger than that of the purple one, which is a direct consequence of the presence of $\mathrm{H}$ atoms in the latter. The deformation of the Lewis base results in a hybridization change of the $\mathrm{C}$ atoms and therefore in a change in their electronegativity. This electronegativity change results unavoidably in an electron density redistribution of the system, whose energetic cost is largely mitigated by the presence of hydrogen atoms, which very easily adapt to these changes. ${ }^{18}$ Similar effects on the stabilization of strained systems and on carbocations and carbanions have been reported before in the literature. ${ }^{27}$ This reasoning seems to be apparently inconsistent with the fact that the fully substituted $\mathrm{F}_{2} \mathrm{CCF}_{2}$ derivative leads to stabilization energies which are still smaller, in absolute value, than those of the unsubstituted parent compound, even though no hydrogen atoms are present. However, Figure 8 shows that, consistently with our previous arguments, the slope of the curve for the $\mathrm{F}_{2} \mathrm{CCF}_{2}$ complex (green curve) is very similar to that of the FCCF complex (yellow curve). The difference arises from the fact that the gap between the interaction energies of $\mathrm{H}_{2} \mathrm{CCH}_{2}$ and $\mathrm{F}_{2} \mathrm{CCF}_{2}$ undistorted complexes $\left(\alpha=180^{\circ}\right)$ is huge $\left(\approx 100 \mathrm{~kJ} \mathrm{~mol}^{-1}\right)$, so even though the slope of the green curve $\left(\mathrm{F}_{2} \mathrm{CCF}_{2}\right)$ is much larger than that of the red curve $\left(\mathrm{H}_{2} \mathrm{CCH}_{2}\right)$ the crossing between both happens at angles much smaller $\left(<140^{\circ}\right)$ than the equilibrium conformation angle $\left(\approx 160^{\circ}\right)$.

In summary, although in both series of complexes the bonding partner is essentially the same, the significant differences in the variation of the interaction energies with the deformation of the Lewis base, explain why the trends of the interaction energies are opposite for both series of complexes.

\section{COOPERATIVE EFFECTS}

\section{Cooperativity Between Beryllium Bonds and Hydro- gen Bonds}

As mentioned in the introduction one of the signatures of non-covalent interactions is cooperativity, a phenomenon that has been very well characterized in hydrogen bonds, but that may also be present when other noncovalent interactions are involved, such as beryllium bonds, which as indicated in previous sections, involve a significant charge transfer from the Lewis base to the

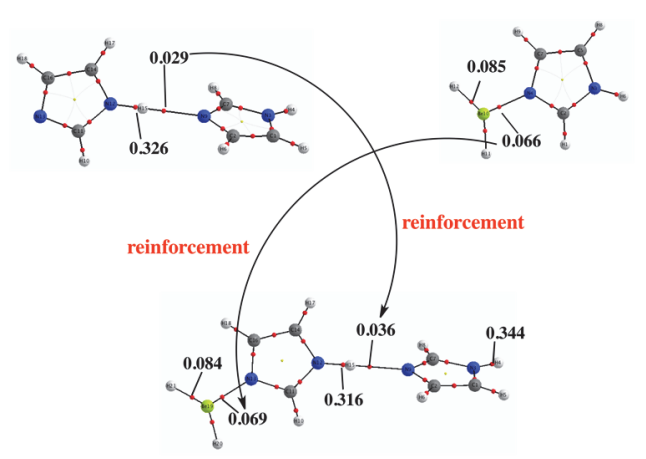

Figure 9. Molecular graphs of imidazole dimer, imidazole$\mathrm{BeH}_{2}$ complex and (imidazole) ${ }_{2} \mathrm{BeH}_{2}$ complex, showing the reinforcement of both the intermolecular hydrogen bond and the beryllium bond in the latter. Red dots denote BCPs. Electron densities are in a.u.

beryllium compound, which is one of the ingredients necessary to observe non-pair wise effects. The cooperativity between beryllium bonds and hydrogen bonds results evident when considering the interactions between imidazole dimers or water clusters and $\mathrm{BeX}_{2}$ derivatives. ${ }^{28}$ Imidazole dimers were characterized both experimentally and theoretically almost two decades ago. ${ }^{29}$ Indeed both monomers are held together by a rather strong intermolecular hydrogen bond, but imidazole also forms strong beryllium bonds with $\mathrm{BeX}_{2}$ derivatives, as beryllium dihydride (see Figure 9). The important finding however is that when both noncovalent interactions are present in the same system, i.e., when the molecular assembly that forms the beryllium bond is the imidazole dimer, rather than the monomer, both the intermolecular hydrogen bond and the beryllium bond become reinforced. ${ }^{28}$

This is nicely illustrated by the changes in the electron densities at the corresponding BCPs, which in the case of the intermolecular hydrogen bond increases from 0.029 to 0.036 a.u., and for the beryllium bond increases from 0.066 to 0.069 a.u. The first reinforcement can be understood by using the acid-base model proposed to explain the cooperativity in HBs. ${ }^{30}$ Indeed, in the formation of the beryllium bond, the imidazole subunit acting as a proton donor behaves simultaneously as electron donor towards $\mathrm{BeH}_{2}$. This significant charge transfer renders this subunit electron deficient and accordingly its $\mathrm{N}-\mathrm{H}$ group becomes a better proton donor reinforcing the intermolecular hydrogen bond, which becomes $0.10 \AA$ shorter. Note that not only the electron density at the HB BCP increases, but that at the $\mathrm{N}-\mathrm{H}$ group acting as proton donor decreases from 0.326 to 0.316 a.u., and consistently the $\mathrm{N}-\mathrm{H}$ bond length increases $0.01 \AA$. Concomitantly, the fact that the imidazole molecule which forms the beryllium bond with the beryllium dihydride is a better proton donor results in an increase of its intrinsic basicity, i.e., in its ability to 
behave as electron donor reinforcing the beryllium bond, which also becomes $0.013 \AA$ shorter.

The interaction of beryllium hydride with water clusters puts in evidence the appearance of cooperative and anti-cooperative effects. ${ }^{31}$ This is very well illustrated when comparing the complexes formed when the water dimer (WD) interacts with $\mathrm{BeH}_{2}$, with those involving water trimers (WT). The local minima for both kinds of clusters are shown in Figure 10, the global minimum being structures [WD: $\left.\mathbf{B e H}_{2}\right] \mathbf{a}$ and $\left[\mathbf{W T}: \mathbf{B e H}_{2}\right] \mathbf{a}$, respectively.

One of the most unexpected results is that the complex in which Be appears tetracoordinated, namely structure [WT: $\left.\mathbf{B e H}_{2}\right] \mathbf{c}$ is not the most stable one, even though $\mathrm{Be}$ is very often called the tetrahedral proton, reflecting its propensity to tetracoordinate. ${ }^{32-34}$ This structure can be seen as the result of the solvation of the Be tetracoordinated complex $\left[\mathbf{W D}\left(\mathbf{B e H}_{2}\right)\right] \mathbf{b}$. A comparison of the molecular graph of $\left[\mathbf{W T}\left(\mathbf{B e H}_{2}\right)\right] \mathbf{c}$ with that of [ $\left.\mathbf{W D}\left(\mathbf{B e H}_{2}\right)\right] \mathbf{b}$ shows that the $\mathbf{A B}$ beryllium bond becomes clearly reinforced, whereas the other AC beryllium bond remains unperturbed. Also, the BD HB between both water molecules is stronger than in the water dimer (BCP electron density 0.025 a.u.). However, these bond reinforcements are not enough to compensate the effects that stabilize the global minimum [WT( $\mathbf{B e H} 2)] \mathbf{a}$. Indeed, when the molecular graph of the complex $\left[\mathbf{W T}\left(\mathbf{B e H}_{2}\right)\right] \mathbf{a}$ is compared with that of $\left[\mathbf{W D}\left(\mathbf{B e H}_{2}\right)\right] \mathbf{a}$, one may observe that besides the new, rather strong, HB

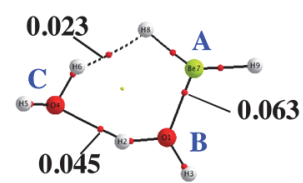

[WD: $\left.\mathrm{BeH}_{2}\right] \mathbf{a}$

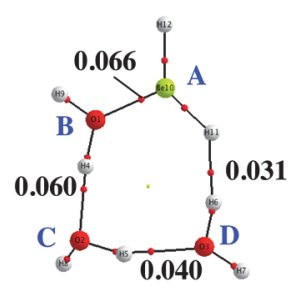

[WT:BeH $\left.{ }_{2}\right] \mathrm{a}$

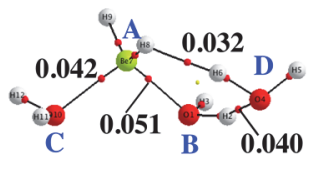

[WT: $\left.\mathrm{BeH}_{2}\right] \mathrm{c}$

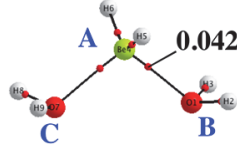

[WD: $\left.\mathrm{BeH}_{2}\right] \mathrm{b}$

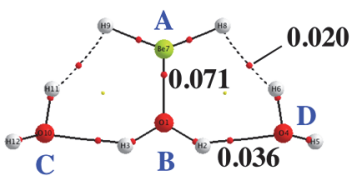

[WT:BeH $\left.{ }_{2}\right] b$

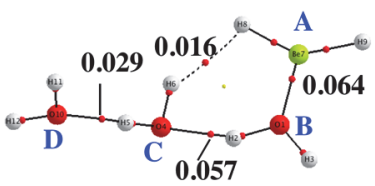

$\left[\mathrm{WT}: \mathrm{BeH}_{2}\right] \mathrm{d}$
Figure 10. Molecular graphs of the clusters formed between water dimer (WD) and trimers (WT) and $\mathrm{BeH}_{2}$. Red dots denote BCPs. Electron densities are in a.u.

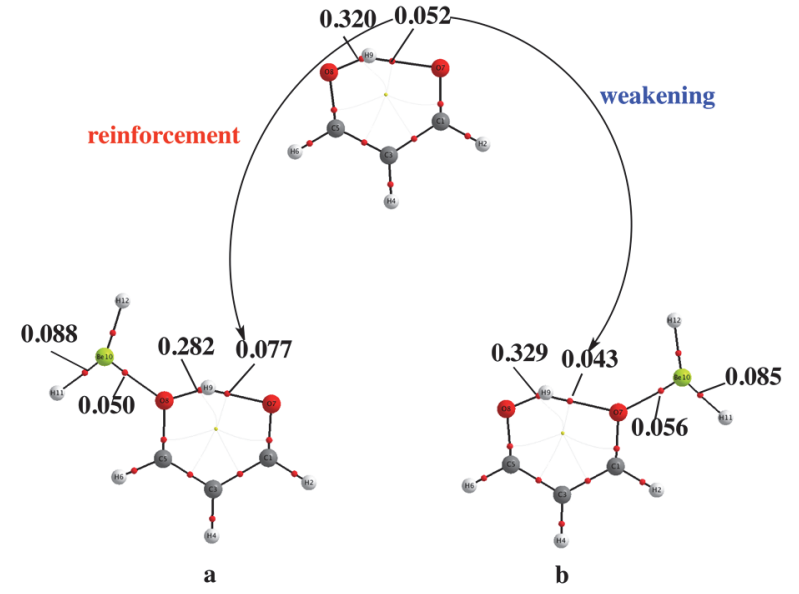

Figure 11. Molecular graphs of the malonaldehyde and its complexes when $\mathrm{BeH}_{2}$ is attached to its $\mathrm{O}-\mathrm{H}$ group (a) or to its carbonyl group (b). Red dots denote BCPs. Electron densities are in a.u.

formed between $\mathbf{C}$ and $\mathbf{D}$, the electron density at the $\mathbf{A B}$ beryllium bond, at the BC HB and at the DA dihydrogen bond (CA in the dimer) clearly increases. The formation of [WT( $\left.\left(\mathbf{B e H}_{2}\right)\right] \mathbf{b}$ leads to both cooperative and anti-cooperative effects. The electron density at the AB beryllium bond increases on going from $\left[\mathbf{W D}\left(\mathbf{B e H}_{2}\right)\right] \mathbf{a}$ to $\left[\mathbf{W T}\left(\mathbf{B e H}_{2}\right)\right] \mathbf{b}$ but the electron density at the $\mathbf{C B}$ and BD HBs and at the AC and AD dihydrogen bonds decreases. The enhancement in the stability of the beryllium bond reflects the increase in the electron donor capacity of the water molecule $\mathbf{B}$ interacting with $\mathrm{BeH}_{2}$ because it is acting as a double proton donor, but for the same reason, the HBs between this water molecule and the other two become weaker. ${ }^{31}$

Cooperativity is also sizable when the intramolecular hydrogen bonds are involved in the interaction with beryllium bonds. A paradigmatic example is provided by malonaldehyde. ${ }^{28}$

Figure 11 shows the significant changes undergone by the intramolecular hydrogen bond when malonaldehyde interacts with $\mathrm{BeH}_{2}$, and these changes depend on the site to which the beryllium dihydride molecule is attached. The association to the $\mathrm{OH}$ group leads to a dramatic increase of its intrinsic acidity which results in a concomitant reinforcement of the intramolecular HB that shrinks $0.157 \AA$, whereas the $\mathrm{OH}$ bond length increases $0.034 \AA$. Consistently the electron density at the $\mathrm{HB}$ and at the $\mathrm{OH}$ BCPs increases and decreases by 0.025 and 0.038 a.u., respectively. Conversely, the attachment of $\mathrm{BeH}_{2}$ to the carbonyl group of malonaldehyde results in a dramatic decrease of its intrinsic basicity leading to a much weaker intramolecular HB, whose length increases $0.074 \AA$, whereas the $\mathrm{OH}$ bond shrinks $0.010 \AA$. Again, consistently, the electron densities at the corresponding BCPs decrease and increase by 0.009 a.u., respectively. ${ }^{28}$ 


\section{Effects of the Cooperativity on the Self-assembling of Ditopic Systems}

The significant Lewis acidity of beryllium derivatives permits to design interesting ditopic systems, i.e. molecular systems that have two separated binding regions, by introducing a $-\mathrm{BeR}$ group as the terminal substituent in a good Lewis base. Such compounds would be good candidates to form chains of complexes attached via beryllium bonds. The first systems of this kind explored by our groups were the (iminomethyl)beryllium hydride and (iminomethyl)beryllium fluoride $[\mathrm{HC}(\mathrm{BeX})=\mathrm{NH}, \mathrm{X}$ $=\mathrm{H}, \mathrm{F}$ ] (see Scheme 1). ${ }^{35}$ In this overview we will focus our attention exclusively on the latter.

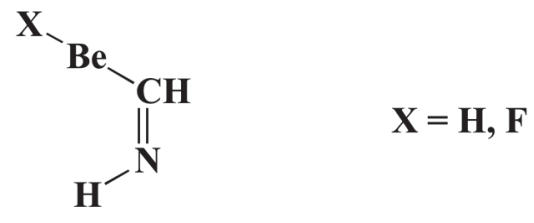

Scheme 1. (Iminomethyl)beryllium hydride and (iminomethyl)beryllium fluoride ditopic systems.

As it could be anticipated in the light of the discussions of previous sections, the interaction between two monomers of (iminomethyl)beryllium fluoride (IMBF) lead to the formation of a rather strong beryllium bond in which the imino nitrogen of one of the monomers behaves as a Lewis base by donating charge to the Be atom of the other monomer acting as a Lewis acid. The strength of this $\mathrm{N}-\mathrm{Be}$ linkage is mirrored in the short N-Be distance (1.75 $\AA$ ), which is only slightly longer than the van der Waals radium of the $\mathrm{N}$ atom. However, what is of importance is the strong cooperativity observed when the trimer is formed. Indeed, the two $\mathrm{N}-\mathrm{Be}$ bonds are now stronger and accordingly, the $\mathrm{N}-\mathrm{Be}$ distance shrinks $0.03 \AA$, the electron density at the $\mathrm{N}-\mathrm{Be} \mathrm{BCP}$ increases by 0.005 a.u. and the interaction energy per monomer goes from $-119.0 \mathrm{~kJ} \mathrm{~mol}^{-1}$ in the dimer to $-137.0 \mathrm{~kJ} \mathrm{~mol}^{-1}$ in the trimer. ${ }^{35}$ Similar cooperative effects, as we shall discuss later, enter into play also in the stabilization of larger $n$-mers. It is important to mention that for the tetramer and for longer $n$-mers a cyclic self-assembling arrangement is also possible. In Figure 12 the two possible conformations for the decamer, linear and cyclic, are shown. Systematically the cyclic structure is found to be more stable than the linear one, because the former has one more beryllium bond than the latter. ${ }^{35}$ For the particular case of the decamer this energy gap amounts to $235.5 \mathrm{~kJ} \mathrm{~mol}^{-1}$. This gap is smaller (by $13 \mathrm{~kJ} \mathrm{~mol}^{-1}$ ) in terms of free energies because the cyclic structure is entropically disfavored. However, the extra beryllium bond which stabilizes the cyclic structures more than compensate the entropic stability loss, and also in terms of free energies the cyclic structures are more stable than the linear ones.

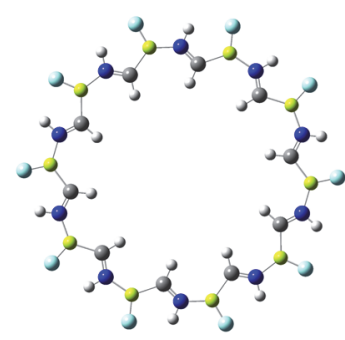

(a)

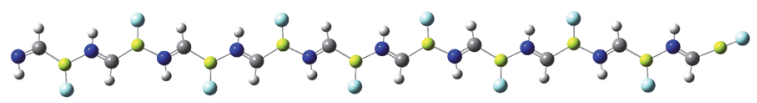

(b)

Figure 12. The two possible conformations, cyclic (a) and linear (b) of the decamer of IMBF.

Cooperative effects for the different $n$-mers are nicely reflected in the length of the beryllium bond formed. As mentioned before the $\mathrm{Be}-\mathrm{N}$ distance decreases significantly on going from the dimer to the trimer; but on moving to longer $n$-mers, it is observed (see Figure 13a) that the shortening strongly depends on the relative position of the monomers involved in the beryllium bond, so that systematically the shortest $\mathrm{Be}-\mathrm{N}$ distances are those between the monomers at the center of the chain and they increase steadily when moving to the ends of the chain. Also importantly, as clearly shown in Figure 13a, the overall shortening of the central $\mathrm{Be}-\mathrm{N}$ linkages is the larger the longer the chain, so the shortest $\mathrm{Be}-\mathrm{N}$ distance $(1.672 \AA)$ is found for the central units of the decamer. Consistently, the variation of the electron densities at the corresponding BCPs is the opposite, and the central units exhibit the beryllium bonds with the larger values of the electron density (See Figure 13b). It is also worth noting that cooperative effects have also a significant and opposite influence on the $\mathrm{C}-\mathrm{Be}$ bond lengths. Indeed, the significant amount of charge received by the Be-F group leads to a significant electron density redistribution. Part of this charge populates the initially empty $p$ orbital of Be and accordingly its hybridization changes. This is reflected in a loss of linearity and in a weakening of the $\mathrm{Be}-\mathrm{C}$ bond, whose length increases as shown in Figure 13c. Coherently with our previous discussion, this figure shows that the lengthening of the $\mathrm{Be}-\mathrm{C}$ bond also depends on the relative position of the IMBF units within the $n$-mer, due to the enhancement of cooperativity when moving towards its center. ${ }^{35}$

Finally, it has been shown that not only the structural parameters, and the electrons densities clearly reflect the significant cooperative effects along the series of $n$-mers discussed above, but also their NMR magnetic properties. Indeed the ${ }^{13} \mathrm{C}$ chemical shifts show exactly the same behavior as the $\mathrm{Be}-\mathrm{N}$ distances 

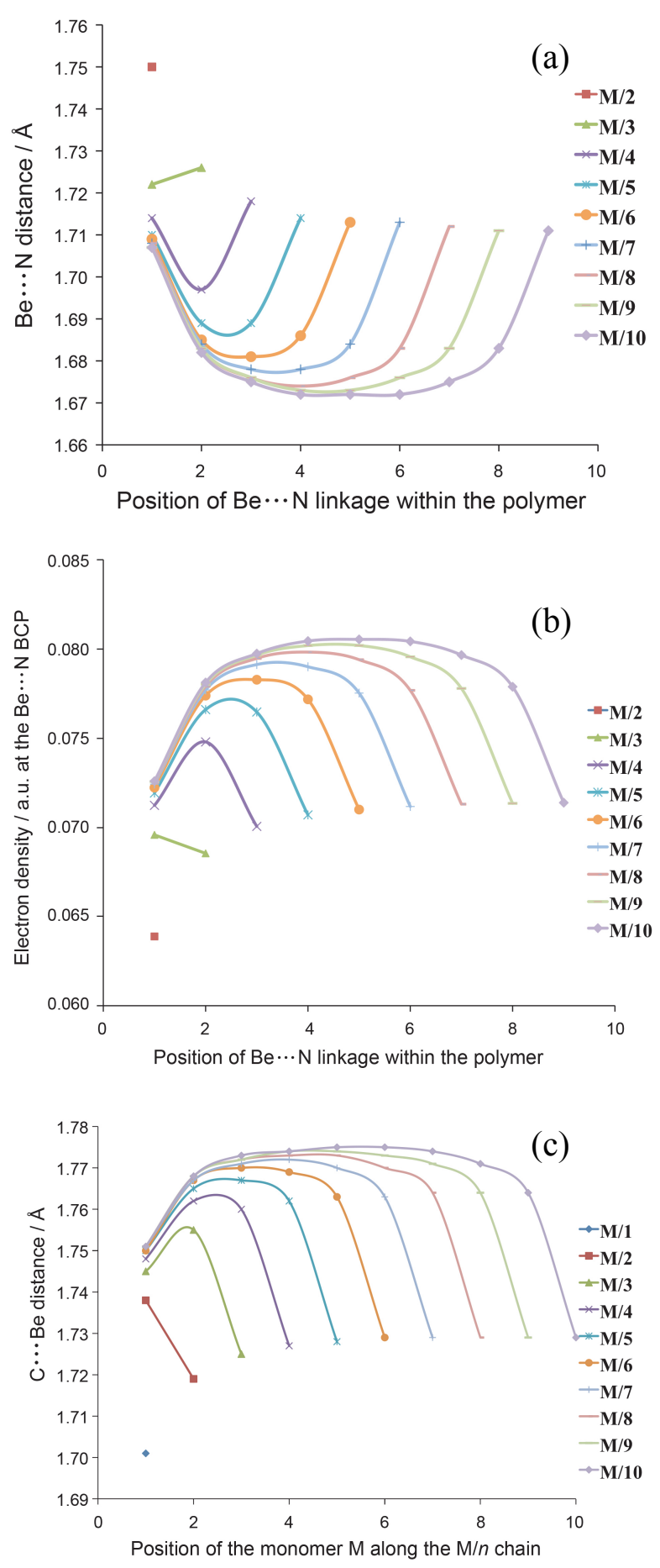

Figure 13. Evolution of: the $\mathrm{Be}-\mathrm{N}$ distances (a), the electron densities at the $\mathrm{Be}-\mathrm{N}$ BCPs (b), the $\mathrm{Be}-\mathrm{C}$ bond length in linear $n$-mers $(\mathrm{M} / 1-\mathrm{M} / 10)$ of IMBF (c).

shown in Figure 13a. In other words, the chemical shifts also depend on the size of the $n$-mer and on the position of the atom along the chain. In fact, the ${ }^{13} \mathrm{C}$ chemical shifts are more negative for the carbon atoms close to the center of the chain than for the atoms close to its ends. Also, a similar size effect as the one discussed above for the interatomic distances is observed for the chemical shifts. ${ }^{35}$

It should also be mentioned that the formation of the $\mathrm{N}-\mathrm{Be}$ beryllium bonds has a dramatic effect on the ${ }^{15} \mathrm{~N}$ chemical shifts. Whereas the ${ }^{15} \mathrm{~N}$ chemical shifts for the $\mathrm{N}$ of the terminal monomers and therefore not participating in any beryllium bond are between -183 and $-146 \mathrm{ppm}$, the values for the nitrogen atoms participating in the beryllium bonds are much smaller in absolute value, between -60 and -15 ppm. $^{35}$

\section{EFFECTS ON THE INTRINSIC PROPERTIES OF THE INTERACTING MONOMERS}

The dissociation of an acid to its conjugate base and a proton is one of the most important reactions in chemistry; acidity is maybe the most relevant physicochemical property of a molecular system from a biological point of view. The ability of a given compound to lose a proton is related to its relative stability with respect to its conjugated base; therefore, the creation of new noncovalent interactions in a molecular system, as those we describe in this paper, plays a crucial role on modifying acidity properties when compared to non interacting units. ${ }^{36}$ Several examples of this kind were studied in detail by our group in recent years. ${ }^{37-41}$

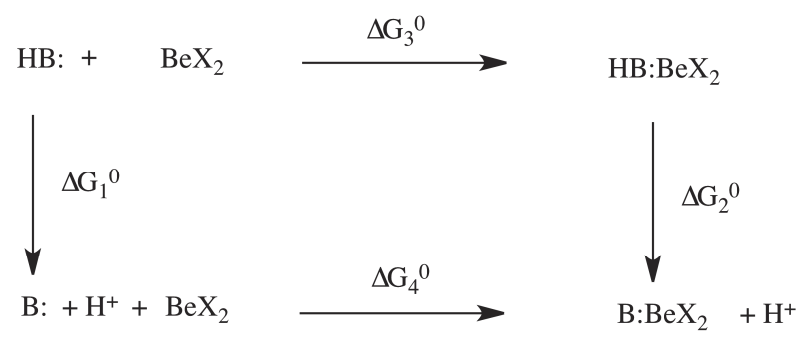

Scheme 2. Thermodynamic cycle associated with the acidity enhancement of a general HB Brønsted acid upon complexation with $\mathrm{BeX}_{2}$ compounds.

As a general rule, it has been observed that when a given compound forms a beryllium bond, the conjugated base becomes a much better electron donor than the acid from which it comes as compared with the same acid-base pair in absence of beryllium bonds, resulting in an acidity enhancement triggered by the beryllium bond. This acidity enhancement is the consequence of the significant amount of charge transferred from the Lewis base towards the available empty orbitals of the beryllium compound, accompanied, as explained in previous sections, by the corresponding deformation mainly of the $\mathrm{BeX}_{2}$ subunit. Scheme 2 summarizes the thermodynamics underlying these processes, paying attention to changes on Gibbs free energy. $\Delta G_{1}{ }^{0}$ corresponds to the dissociation 
process of the free acid, whereas $\Delta G_{2}^{0}$ is the dissociation process of the same acid in presence of beryllium bonds. $\Delta G_{3}{ }^{0}$ and $\Delta G_{4}{ }^{0}$ are the free energies associated to the complexation process of the free acid and its conjugate base with the beryllium compound, respectively. Since $\Delta G_{4}{ }^{0}$ is usually twice as large as $\Delta G_{3}{ }^{0}$, then $\Delta G_{1}{ }^{0}$ has to be considerably larger than $\Delta G_{2}{ }^{0}$. This is equivalent to saying that $\mathrm{HB}-\mathrm{BeX}_{2}$ is more acidic than its related free acid.

Let's see some particular examples of this acidity enhancement triggered by the formation of a beryllium bond in the system. Table 1 contains $\Delta H_{1}{ }^{0}$ and $\Delta H_{2}{ }^{0}$ values (related to $\Delta G_{1}{ }^{0}$ and $\Delta G_{2}{ }^{0}$ in the general cycle described above) for some representative compounds upon association with beryllium dihydride. Typical bases in the gas phase like water, imidazole, pyrazole or aniline become more acidic than phosphoric acid, and an unsaturated hydrocarbon as ethylene is as acidic as formic acid upon complexation. ${ }^{41}$ This effect is even more dramatic when $\mathrm{BeH}_{2}$ is replaced by $\mathrm{BeCl}_{2}$, and for instance aniline reaches an acidity value of $1316.4 \mathrm{~kJ}$ mol $^{-1}$, almost as acidic as chloric acid. ${ }^{41}$

Sometimes, more than one non-covalent interaction is involved in the acidity enhancement phenomenon, as it is the case for squaric acid $\mathrm{C}_{4} \mathrm{O}_{4} \mathrm{H}_{2}$ and its derivatives. ${ }^{42}$ Left part of Figure 14 shows the molecular graphs of isolated squaric acid and its complex with $\mathrm{BeF}_{2}$, in which two non covalent interactions are present: a beryllium bond $(\mathrm{O}-\mathrm{Be})$ plus a hydrogen bond $(\mathrm{OH} \cdots \mathrm{F})$. In this case, $\Delta G_{1}{ }^{0}$ and $\Delta G_{2}{ }^{0}$ values are 1291.0 and $1183.0 \mathrm{~kJ} \mathrm{~mol}^{-1}$, respectively, whereas $\Delta G_{3}{ }^{0}$ and $\Delta G_{4}{ }^{0}$ values are -92.2 and $-200.2 \mathrm{~kJ} \mathrm{~mol}^{-1}$ at $\mathrm{G} 4$ level of theory. ${ }^{42} \mathrm{~A}$ much larger gaining on stability of the conjugated squaric anion on complexing $\mathrm{BeF}_{2}$ is related with an acidity enhancement of more than $100 \mathrm{~kJ} \mathrm{~mol}^{-1}$ in complexed squaric acid. This effect is nicely reflected on the electron density values at the $\mathrm{BCP}$ in $\mathrm{O}-\mathrm{H}$ bond: from 0.361 a.u. (free acid) to 0.310 a.u. (complex). Although more acidic than squaric acid, the acidity enhancement is not so remarkable in the sulfur derivative $\mathrm{C}_{4} \mathrm{~S}_{4} \mathrm{H}_{2},\left(71.9 \mathrm{~kJ} \mathrm{~mol}^{-1}\right)$ in which changes on $\mathrm{BCPs}$ density values are smaller from the free acid to the complex (0.212 a.u. to 0.207 a.u). Beryllium and hydrogen

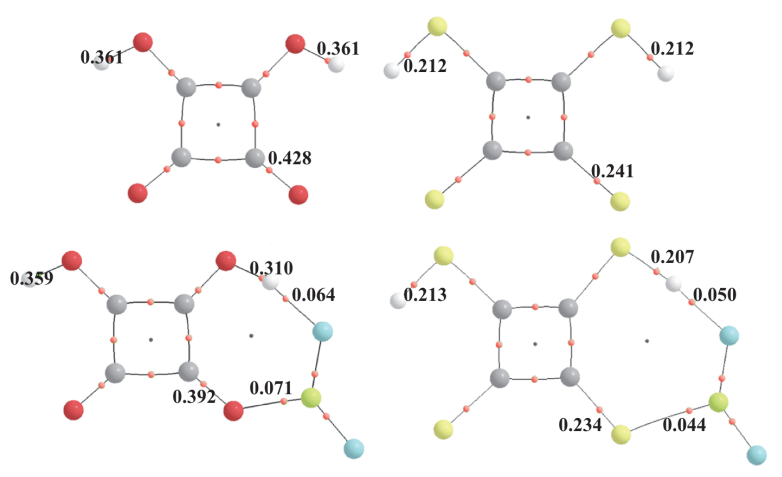

Figure 14. Molecular graphs of free squaric acid $\mathrm{C}_{4} \mathrm{O}_{4} \mathrm{H}_{2}$ and its sulfur derivative $\mathrm{C}_{4} \mathrm{~S}_{4} \mathrm{H}_{2}$, along with their corresponding $\mathrm{BeF}_{2}$ complexes. Red and green dots denote BCPs and RCPs, respectively. Electron densities are expressed in a.u.

bonds are stronger in the squaric acid case than in its sulfur derivative. ${ }^{42}$

Other Lewis acids different from beryllium, as boron or aluminum, can also induce significant acidity enhancements. ${ }^{36-39}$ Similar closed-shell interactions as those described for beryllium compounds are found in boranes $\mathrm{BX}_{3}$ and alanes $\mathrm{AlX}_{3}$, compounds that suffer a significant distortion when forming dative bonds with Lewis basis as it was previously shown on preceding sections. Therefore, the intrinsic acidity of phosphine is notably different from that of phosphine-boranes (seventeen orders of magnitude greater in terms of the corresponding equilibrium constant), but the most relevant finding is that these theoretical predictions are fully ratified by the experimental evidence. In fact, high-level ab initio calculations predict that phenylphosphineborane complex should be $76 \mathrm{~kJ} \mathrm{~mol}^{-1}$ more acidic than the isolated phosphine, in excellent agreement with the experimental FT-ICR measurements that yield for this acidity gap $82.6 \pm 3.3 \mathrm{~kJ} \mathrm{~mol}^{-1} .{ }^{37}$ This acidity enhancement is even larger when the phosphine is replaced by the corresponding amine, and the acidity gap between aniline-borane and the free aniline is $136 \mathrm{~kJ} \mathrm{~mol}^{-1} .{ }^{39}$

It is worth noting that the acidity enhancement is also larger for phosphine-alanes ${ }^{38}$ than for the corresponding phosphine-borane analogues, an unexpected

Table 1. Proton dissociation enthalpies for some selected bases and their complexes with $\mathrm{BeH}_{2}$ at $\mathrm{G} 4$ level of theory. The third column shows the acidity enhancement.

\begin{tabular}{cccc}
\hline Base & $\Delta H_{1}{ }^{0} / \mathrm{kJ} \mathrm{mol}^{-1}$ & $\Delta H_{2}{ }^{0} / \mathrm{kJ} \mathrm{mol}^{-1}$ & $\left(\Delta H_{1}{ }^{0}-\Delta H_{2}{ }^{0}\right) / \mathrm{kJ} \mathrm{mol}^{-1}$ \\
\hline $\mathrm{H}_{2} \mathrm{O}$ & 1629.9 & 1360.0 & 269.9 \\
$\mathrm{NH}_{3}$ & 1688.8 & 1435.0 & 253.8 \\
$\mathrm{H}_{2} \mathrm{C}=\mathrm{CH}_{2}$ & 1710.0 & 1441.5 & 268.5 \\
imidazole $\mathrm{C}_{3} \mathrm{H}_{3} \mathrm{~N}_{2}$ & 1463.2 & 1351.8 & 111.4 \\
pyrazole $\mathrm{C}_{3} \mathrm{H}_{3} \mathrm{~N}_{2}$ & 1483.4 & 1374.8 & 108.6 \\
aniline $\mathrm{C}_{6} \mathrm{H}_{5} \mathrm{NH}_{2}$ & 1537.8 & 1358.9 & 178.9 \\
\hline
\end{tabular}




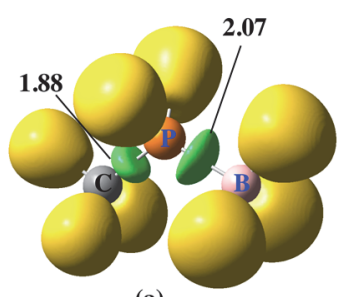

(a)

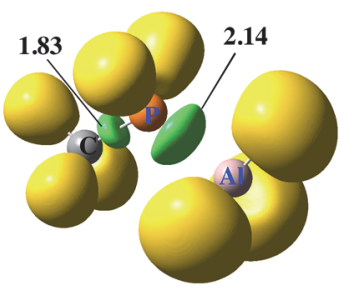

(b)

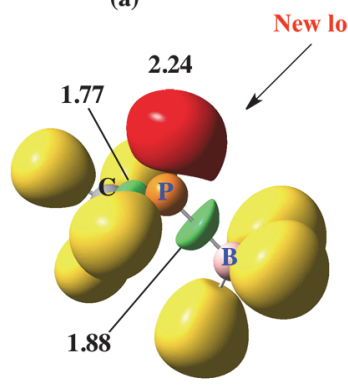

(c)

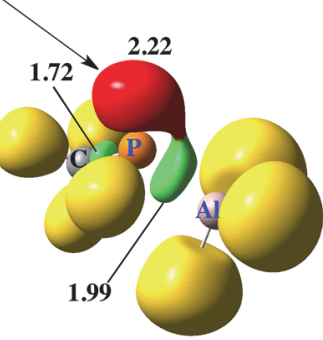

(d)
Figure 15. $\mathrm{ELF}(=0.85)$ for the $\mathrm{CH}_{3} \mathrm{PH}_{2}: \mathrm{XH}_{3}$ complexes: $\mathrm{X}=$ $\mathrm{B}(\mathrm{a}) ; \mathrm{X}=\mathrm{Al}$ (b) and their corresponding $\mathrm{P}$ deprotonated species ((c) and (d)). Green lobes denote disynaptic basins involving two heavy atoms. Yellow lobes are disynaptic basins in which $\mathrm{H}$ is one of the atoms involved. Red lobes correspond to lone pairs. The populations shown are $\mathrm{e}^{-}$.

result since boranes should be, in principle, better Lewis acids than alanes. Once again, the reason behind this phenomenon is the greater stabilization of the deprotonated phosphine which is significantly larger in complexes with alanes than in complexes with boranes. On passing from neutral to deprotonated phosphine, a new lone electron pair from $\mathrm{P}$ atom is available in both kind of complexes. However, this lone electron pair is much more delocalized in the alane complex than in the borane complex, as revealed by the ELF analysis shown in Figure 15 . In the $\mathrm{P}-\mathrm{Al}$ bonding region the disynaptic basin is richer in electrons than the analogue $\mathrm{P}-\mathrm{B}$ region, resulting in a larger stability of the deprotonated alane complex that is related with the unexpected acidity enhancement of phosphine-alane complexes. ${ }^{38}$

\section{SPONTANEOUS LOSS OF $\mathrm{H}_{2}$}

The formation of beryllium bonds may produce an acidity enhancement that finally can result in a spontaneous proton-transfer processes. ${ }^{43,44}$ In the particular case of squaric acid and its derivatives, ${ }^{45}$ a remarkable increase in acidity is observed upon complexation with beryllium difluoride, as a consequence of the electron density redistribution in the system caused by the beryllium bond formation as previously described.

As a last piece in this chain of physicochemical transformations, when beryllium difluoride is replaced by beryllium dihydride this redistribution of charge leads to a spontaneous loss of a hydrogen molecule. For $\mathrm{BeH}_{2}$ the stable conformation shown in Scheme 3 in which a beryllium bond and a dihydrogen bond coexist in the complex is no longer stable, and the dihydrogen bonded complex presents a rather small energy barrier in terms of electronic energy to produce $\mathrm{H}_{2}$, that vanishes in terms of Gibbs free energy. This exergonic process is illustrated on Scheme 3, resulting in a new neutral $\mathrm{C}_{4} \mathrm{X}_{4} \mathrm{H}^{*} \mathrm{BeH}$ complex plus a hydrogen molecule. At $\mathrm{G} 4$ level of theory, the total Gibbs free energy released in the reaction $\mathrm{C}_{4} \mathrm{O}_{4} \mathrm{H}_{2}+\mathrm{BeH}_{2} \rightarrow \mathrm{C}_{4} \mathrm{O}_{4} \mathrm{H}^{*} \mathrm{BeH}+\mathrm{H}_{2}$ is $-195.7 \mathrm{~kJ} \mathrm{~mol}^{-1}$, as a result of the spontaneous proton transfer from the squaric moiety, induced by the beryllium bond. ${ }^{45}$ This finding might be relevant as beryllium hydride has been considered a high hydrogen storage capacity material.

\section{BONDING PERTURBATION AND COUPLING CONSTANTS: THE CASE OF HALOGEN BONDS}

The subject of halogen bonding is very active, ${ }^{46-49}$ and cannot been covered, even briefly, in a review like the present one. For this reason and because this is an original approach of our research, we will summarize the part concerning indirect spin-spin coupling constants (SSCC) in halogen-bonded complexes. The molecule we have almost always used is chlorine fluoride $(\mathrm{FCl})$ because it has a large dipole interacting with the Lewis

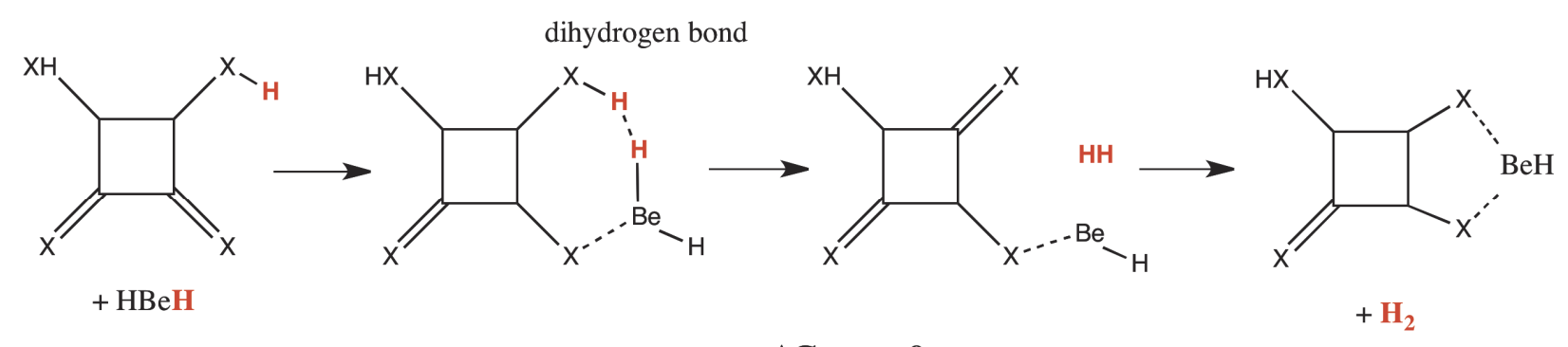

Scheme 3. Spontaneous hydrogen loss process on squaric acid and squaric acid derivatives $(X=O, S, S e)$. 
base (LB) by the chlorine end. All the geometry calculations were done at the MP2/aug'-cc-pVTZ level and the SSCC ones, using the equation-of-motion (EOM) with the coupled-cluster-singles-and-doubles (CCSD) methods. That SSCC is a very interesting probe of the bond between two atoms $\mathrm{A}$ and $\mathrm{B}$ is known from McConnell's time (1956) when he related ${ }^{\mathrm{n}} J_{\mathrm{AB}}$ to the bond-order between atoms A and B. ${ }^{50}$ This is particularly relevant for non-covalent interactions, like SSCC through hydrogen bonds. ${ }^{51}$

We studied several kinds of complexes (Scheme 4) depending on the LB being a ${ }^{15} \mathrm{~N}, a{ }^{13} \mathrm{C}, \mathrm{a}{ }^{31} \mathrm{P}$ or a ${ }^{17} \mathrm{O}$ atom derivative. Three couplings were calculated and discussed: ${ }^{1} J_{\mathrm{YCl}}$ (usually, ${ }^{1} J_{\mathrm{FCl}}$ ), ${ }^{1 \mathrm{X}} J_{\mathrm{ClLB}}$ and ${ }^{2 \mathrm{X}} J_{\mathrm{YLB}}$ (usually ${ }^{2 \mathrm{X}} J_{\mathrm{FLB}}$ ). The superscript $\mathrm{X}$ stands for halogen by analogy with the $\mathrm{H}$ superscript for hydrogen in HBs.

\begin{tabular}{|c|c|}
\hline \multicolumn{2}{|c|}{$\mathrm{Y}-\mathrm{Cl} \cdots \ldots$ LB } \\
\hline $\begin{array}{l}\mathrm{F}-\mathrm{Cl} \cdots \cdot \ldots \mathbf{N R} \\
\mathrm{NR}=\mathrm{NCH}, \mathrm{NH}_{3}, \ldots \\
\mathrm{F}-\mathrm{Cl} \cdots \cdot \ldots \mathrm{NCX}\end{array}$ & $\mathrm{F}-\mathrm{Cl} \cdots \cdot \mathrm{CNX}$ \\
\hline $\mathrm{F}-\mathrm{Cl} \cdots \mathrm{N}\left(\mathrm{sp}, \mathrm{sp}^{2}, \mathrm{sp}^{3}\right)$ & \\
\hline $\mathrm{F}-\mathrm{Cl} \cdot \ldots \mathrm{PCX}$ & X'..HBO $\cdots \cdot$ \\
\hline $\mathrm{Y}-\mathrm{Cl} \cdot \mathrm{PH}_{2} \mathrm{~F}$ & 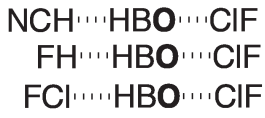 \\
\hline
\end{tabular}

Scheme 4. Halogen-bonded complexes.

Our first paper concerned $\mathrm{F}-\mathrm{Cl} \cdots \mathrm{N}$ systems with a large variety of nitrogen derivatives and the relation of the different $\mathrm{SSCC}$ with the $\mathrm{F}-\mathrm{Cl}$ and the $\mathrm{F} \cdots \mathrm{N}$ distances. ${ }^{52}$ When the $\mathrm{Cl} \cdots \mathrm{N}$ distance decreases the structures change from traditional XBs, to chlorine-shared XB, to finally ion-pairs (see Scheme 5). Along the chlorinetransfer coordinate in $\mathrm{F}-\mathrm{Cl} \cdots \mathrm{NH}_{3},{ }^{1} J_{\mathrm{FCl}}$ decreases but remains positive, ${ }^{2 \mathrm{X}} \mathrm{J}_{\mathrm{FN}}$ continuously increases in absolute value, and ${ }^{1 \times} J_{\mathrm{CIN}}$ initially increases in absolute value and then decreases but remains negative. Its value in the ion-pair complex does not approach the value of ${ }^{1} J_{\mathrm{CIN}}$ for isolated $\mathrm{H}_{3} \mathrm{NCl}^{+}$. The problem of chlorineshared $v s$. ion-pair halogen bond has been extended to $s p, s p^{2}$ and $s p^{3} \mathrm{~N}$ atom derivatives. ${ }^{53}$

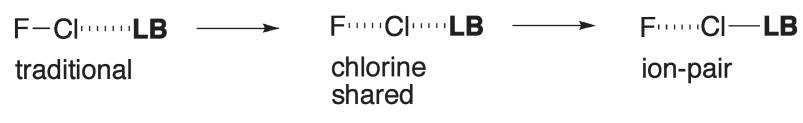

Scheme 5. Kinds of halogen bonds as a function of the $\mathrm{Cl} \cdots \mathrm{LB}$ distance. LB stands for Lewis Base.

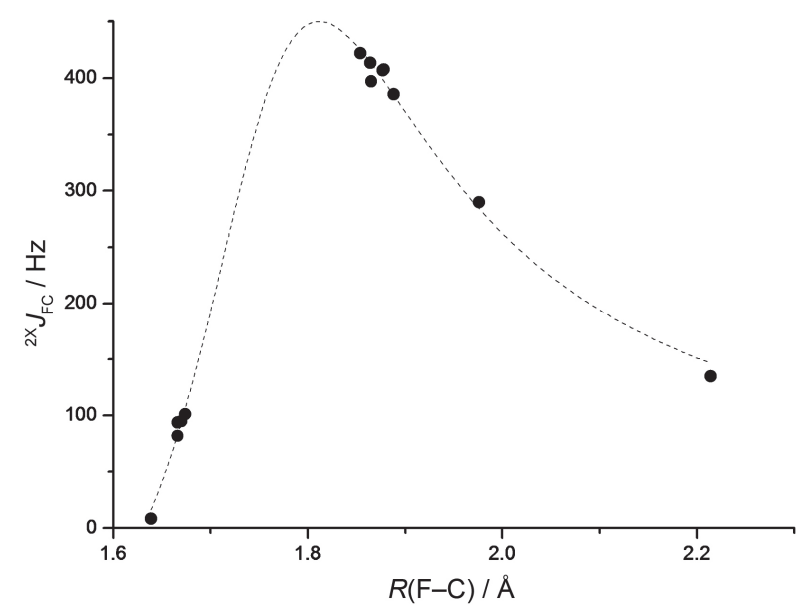

Figure 16. ${ }^{2 \mathrm{X}} J_{\mathrm{FC}} v s . \mathrm{R}(\mathrm{F}-\mathrm{Cl})$ for complexes $\mathrm{FCl}: \mathrm{CNX}$.

Variations of the ${ }^{2} \mathrm{~J}_{\mathrm{FC}}$ coupling constants for $\mathrm{F}-\mathrm{Cl} \cdots \mathrm{CNX}$ systems were also reported. ${ }^{54}$ (see Figure 16).

We move from $\mathrm{N}$ to $\mathrm{P}$ to explore the pnicogen group 15, replacing nitriles by ylidenephosphines. ${ }^{55} \mathrm{We}$ found two minima that we name configuration I and configuration II (with the $\pi$ cloud of the triple bond) (see Scheme 6).

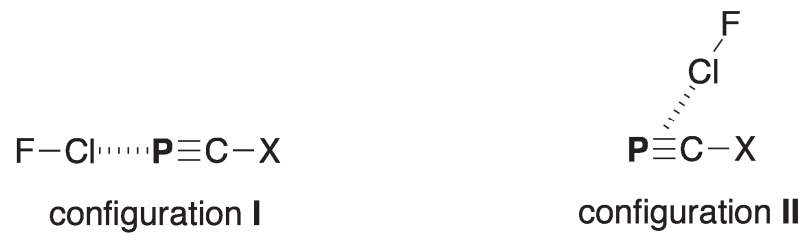

Scheme 6. Configurations I and II for halogen bonds involving ylidenephosphines.

We have represented in Figure 17 the surprising result that both kind of complexes belong to the same curve when ${ }^{1} J_{\mathrm{FCl}}$ is plotted against $\mathrm{R}(\mathrm{F}-\mathrm{Cl})$.

${ }^{1} \mathrm{~J}_{\mathrm{FCl}}$ coupling constants decrease to a greater extent for configuration II complexes compared to configuration $\mathbf{I}$, a reflection of the longer $\mathrm{F}-\mathrm{Cl}$ distances in II. Despite shorter $\mathrm{F}-\mathrm{P}$ and $\mathrm{Cl}-\mathrm{P}$ distances in configuration II, ${ }^{2 \mathrm{X}} J_{\mathrm{FP}}$ and ${ }^{1 \mathrm{X}} J_{\mathrm{CIP}}$ values are significantly reduced compared with those for configuration $\mathbf{I}$. The nature of the $\mathrm{F}-\mathrm{P}$ coupling is dramatically different in configurations I and II, as evidenced by the relative importance of PSO (Paramagnetic Spin-Orbit), FC (Fermi Contact), and SD (Spin-Dipole) components. ${ }^{55}$

A more recent work uses a different type of molecules to study $\mathrm{Cl} \cdots \mathrm{P}$ systems: $\mathrm{Y}-\mathrm{Cl} \cdots \mathrm{PH}_{2} \mathrm{~F}^{56}$ The types of halogen bonds, traditional (XB-T), chlorine-shared (XB-S) and ion-pair (XB-IP) were found as well as two kind of pnicogen-bonds (ZB-1 and ZB-2) (see Scheme 7).

The ${ }^{1 \mathrm{X}} J_{\mathrm{PCl}}$ vs. the $\mathrm{P}-\mathrm{Cl}$ distance for complexes with halogen bonds was adjusted using a Morse curve (Figure 18). At long distances, ${ }^{1} J_{\mathrm{PCl}}$ values for 

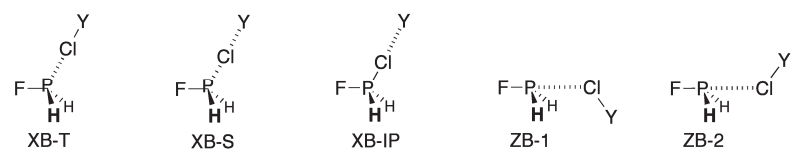

Scheme 7. Types of halogen and pnicogen bonds found for the interactions between $\mathrm{FPH}_{2}$ and $\mathrm{FCl}$.

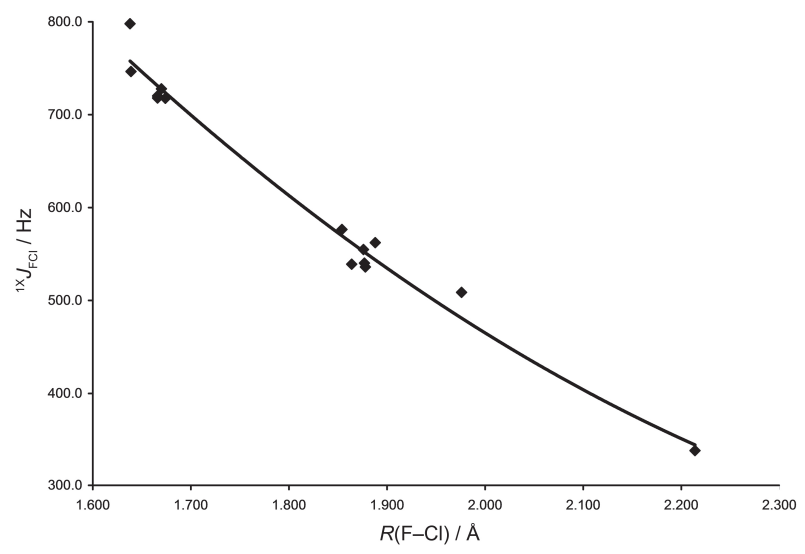

Figure 17. ${ }^{1} J_{\mathrm{FCl}} v s$. the $\mathrm{F}-\mathrm{Cl}$ distances for complexes with configuration I and II.

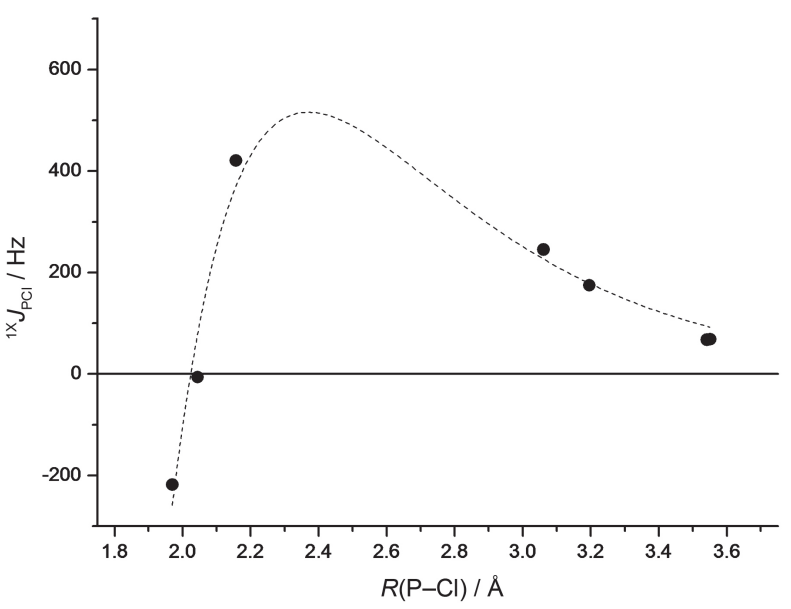

Figure 18. Coupling constant ${ }^{1 \mathrm{X}} J_{\mathrm{PCl}}$ versus the $\mathrm{P}-\mathrm{Cl}$ distance for complexes with halogen bonds.

complexes with traditional halogen bonds increase as the $\mathrm{P}-\mathrm{Cl}$ distance decreases. As this distance decreases further, the curvature changes as the halogen bond changes from traditional to chlorine-shared, and ${ }^{1 \mathrm{X}} J_{\mathrm{PCl}}$ attains its maximum values for chlorine-shared halogen bonds. A further decrease in the $\mathrm{P}-\mathrm{Cl}$ distance leads to a decrease in ${ }^{1 \mathrm{X}} \mathrm{JCl}_{\mathrm{PCl}}$ and eventually to a change of sign as the halogen bond changes from chlorine-shared to ion-pair.

Our last contributions are related to ternary systems where the central part is the ambident HBO (oxoboron) molecule. ${ }^{57,58}$ This compound is a better proton acceptor and a weaker proton donor than $\mathrm{HCN}$ and we

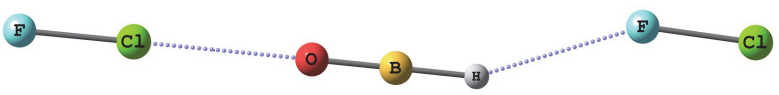

Figure 19. A representation of the $\mathrm{Cl}-\mathrm{F} \cdots \mathrm{HBO} \cdots \mathrm{Cl}-\mathrm{F}$ complex.

have used it to explore non-additive effects with different $X$ and $Z$ molecules (Scheme 4), the most relevant for the present purpose is the complex where $\mathrm{X}=\mathrm{Z}=$ FCl (Figure 19).

Different SSCC as well as the total binding energies were calculated and analyzed for 46 ternary complexes. The cooperativity effects of the ternary complexes have been evaluated. In all cases, the intermolecular distances obtained in the ternary complexes were smaller than the ones in the corresponding binary complexes. From the energetic viewpoint, synergism was evident when the total interaction energy of the ternary complex si compared with the sum of the interaction energy of the two former binary complexes. The larger cooperativity energies where obtained in the complexes where $\mathrm{LiH}$ where involved both as Lewis acid and Lewis base. The non-pairwise binding energy in the ternary complexes was found to correlate with both the binding energies of the $\mathrm{X}: \mathrm{HBO}$ and $\mathrm{HBO}: \mathrm{Z}$ binary complexes.

\section{CONCLUDING REMARKS}

The survey presented along this paper shows four distinctiveness of non-covalent interactions, which arise essentially from the perturbations undergone by the electron densities of the interacting subunits, triggered by polarization effects. These changes in the electron density distribution are reflected in structural distortions of both interacting subunits, although often they are more significant for one of the species. The geometrical changes do not only imply a certain energetic cost, but they also change the intrinsic properties of the distorted systems, mainly when the changes in the structure are due to changes in the hybridization pattern of some of the active centers involved. In these cases, the calculated interaction energies can only be adequately accounted for if the effects of the distortion on the intrinsic reactivity of the system, and not only their deformation energy, are taken into consideration. The second effect of the electron density redistribution is cooperativity and/or anti-cooperativity, which can be easily understood in terms of acid-base Lewis concepts, because the system that acts as a Lewis base feels its Lewis acidity enhanced, and vice-versa the one that acts as Lewis acid behaves as a better Lewis base. When the interaction involves Lewis bases which contain hydrogen atoms and polarization towards the Lewis acid is significant, the Lewis base can become a strong Brønsted acid. 
Indeed, typical bases, such as aniline, become Brønsted acids stronger than phosphoric acid in the gas phase, upon association with $\mathrm{BH}_{3}$ or with $\mathrm{BeX}_{2}$ derivatives. Therefore this third effect arising from the electron density perturbation may permit to adequately modulate and tune the intrinsic properties of either subunits. A fourth effect is clearly seen when analyzing the magnetic properties of the interacting systems, whose chemical shifts and coupling constants reflect the aforementioned perturbations of the electron density and accordingly the cooperative effects, if they are present. A paradigmatic example is provided by the $n$-mers formed when ditopic systems, in which an active Lewis base center and an active Lewis acid center are at the terminal positions of a molecular compound. These systems may self-assemble very easily due to the stabilizing cooperative effects.

These four signatures are particularly strong when beryllium bonds are formed, because beryllium derivatives are extremely good electron acceptors and therefore very strong Lewis acids. However, they are common to any interaction involving two closed-shell systems, one acting as Lewis acid and the other as Lewis base, and the only difference between the nature of the interactions is quantitative.

Acknowledgements. This work has been partially supported by the Ministerio de Economía y Competitividad (Project No. CTQ2012-35513-C02), the Project MADRISOLAR2, Ref.: S2009PPQ/1533 of the Comunidad Autónoma de Madrid, by Consolider on Molecular Nanoscience CSC2007-00010, and by the CMST COST Action CM1204. AMS acknowledges a FPI contract from the Ministerio de Economía y Competitividad of Spain. A generous allocation of computing time at the CTI (CSIC) and at the CCC of the UAM is also acknowledged.

\section{REFERENCES}

1. J. D. Van der Waals On the Continuity of the Gaseous and Liquid States; PhD Thesis, Edited by J. S. Rowlinson. Dover Phoenix Ed., New York, 2004.

2. The Collected Papers of P. J. W. Debye, Interscience, New York, 1954.

3. W. Heitler and F. London, Z. Phys. 44 (1927) 455. English translation in H. Hettema, Quantum Chemistry, Classic Scientific Papers, World Scientific, Singapore (2000).

4. R. Eisenschitz and F. London, Z. Phys. 60 (1930) 491. English translation in H. Hettema, Quantum Chemistry, Classic Scientific Papers, World Scientific, Singapore (2000).

5. J. E. Lennard-Jones, Proc. R. Soc. Lond. A 106 (1924) 463-477.

6. L. Pauling, The Nature of the Chemical Bond, Cornell University Press, Ithaca, New York, 1939.

7. T. S. Moore and T. F. Winmill, J. Chem. Soc. Trans. 101 (1912) 1635-1676.

8. R. Custelcean and J. E. Jackson, J. Am. Chem. Soc. 120 (1998) 12935-12941.

9. P. Metrangolo and G. Resnati, Chem.-Eur. J. 7 (2001) 25112519.

10. P. Politzer, J. S. Murray, and T. Clark, Phys. Chem. Chem. Phys. 15 (2013) 11178-11189.
11. M. Yáñez, P. Sanz, O. Mó, I. Alkorta, and J. Elguero, J. Chem Theor. Comput. 5 (2009) 2763-2771.

12. S. Zahn, R. Frank, E. Hey-Hawkins, and B. Kirchner, Chem. Eur. J. 17 (2011) 6034-6038.

13. P. Politzer, J. S. Murray, G. V. Janjić, and S. D. Zarić, Crystals 4 (2014) 12-31.

14. O. Mó, M. Yáñez, L. González, and J. Elguero, ChemPhysChem 2 (2001) 465-467.

15. A. E. Reed, L. A. Curtiss, and F. Weinhold, Chem. Rev. 88 (1988) 899-926.

16. B. Swanson, D. F. Shriver, and J. A. Ibers, Inorg. Chem. 8 (1969) 2182-2189.

17. I. Alkorta, J. Elguero, J. E. Del Bene, O. Mo, and M. Yanez, Chem.-Eur. J. 16 (2010) 11897-11905.

18. G. Sánchez-Sanz, I. Alkorta, J. Elguero, M. Yáñez, and O. Mó, Phys. Chem. Chem. Phys. 14 (2012) 11468-11477.

19. R. F. W. Bader, Atoms in Molecules. A Quantum Theory, Clarendon Press, Oxford, 1990.

20. A. D. Becke and K. E. Edgecombe, J. Chem. Phys. 92 (1990) 5397-5403.

21. A. Savin, R. Nesper, S. Wengert, and T. F. Fäsler, Angew. Chem. Int. Ed. Engl. 36 (1997) 1808-1832.

22. T. Brinck, J. S. Murray, and P. Politzer, Inorg. Chem. 32 (1993) 2622-2625.

23. B. D. Rowsell, F. J. Gillespie, and G. L. Heard, Inorg. Chem. 38 (1999) 4659-4662.

24. F. Bessac and G. Frenking, Inorg. Chem. 42 (2003) 7990-7994.

25. A. Martín-Sómer, A. Lamsabhi, O. Mó, and M. Yáñez, Comput. Theor. Chem. 998 (2012) 74-79.

26. S. L. Stephens, D. P. Tew, V. A. Mikhailov, N. R. Walker, and A. C. Legon, J. Chem. Phys. 135 (2011) 10.

27. K. B. Wiberg, P. V. Schleyer, and A. Streitwieser, Can. J. Chem. 74 (1996) 892-900.

28. O. Mó, M. Yáñez, I. Alkorta, and J. Elguero, J. Chem. Theory Comput. 8 (2012) 2293-2300.

29. R. A. Jockusch and E. R. Williams, J. Phys. Chem. A 102 (1998) 4543-4550.

30. O. Mó, M. Yáñez, and J. Elguero, J. Chem. Phys. 97 (1992) 6628-6638.

31. L. Albrecht, R. J. Boyd, O. Mó, and M. Yáñez, Phys. Chem. Chem. Phys. 14 (2012) 14540-14547.

32. T. M. McCleskey, D. S. Ehler, T. S. Keizer, D. N. Asthagiri, L. R. Pratt, R. Michalczyk, and B. L. Scott, Angew. Chem.-Int. Edit. 46 (2007) 2669-2671.

33. B. L. Scott, T. M. McCleskey, A. Chaudhary, E. Hong-Geller, and S. Gnanakaran, Chem. Commun. 25 (2008) 2837-2847.

34. S. Gnanakaran, B. Scott, T. M. McCleskey, and A. E. Garcia, J. Phys. Chem. B 112 (2008) 2958-2963.

35. I. Alkorta, J. Elguero, M. Yáñez, and O. Mó, Phys. Chem. Chem. Phys. 16 (2014) 4305-4312

36. J. H. Ren, C. J. Cramer, and R. R. Squires, J. Am. Chem. Soc. 121 (1999) 2633-2634.

37. M. Hurtado, M. Yáñez, R. Herrero, A. Guerrero, J. Z. Dávalos, J.-L. M. Abboud, B. Khater, and J. C. Guillemin, Chem.-Eur. J. 15 (2009) 4622-4629.

38. A. Martín-Sómer, A. Lamsabhi, O. Mó, and M. Yáñez, J. Phys. Chem. A 116 (2012) 6950-6954.

39. A. Martín-Sómer, A. Lamsabhi, M. Yáñez, J. Z. Davalos, J. Gonzalez, R. Ramos, and J. C. Guillemin, Chem.-Eur. J. 18 (2012) 15699-15705.

40. O. Mó, M. Yáñez, I. Alkorta, and J. Elguero, J. Mol. Model. 19 (2013) 4139-4145.

41. M. Yáñez, O. Mó, I. Alkorta, and J. Elguero, Chem. -Eur. J. 35 (2013) 11637-11643.

42. M. M. Montero-Campillo, A. M. Lamsabhi, O. Mó, and M. Yáñez, J. Mol. Model. 19 (2013) 2759-2766. 
43. M. Yáñez, O. Mó, I. Alkorta, and J. Elguero, Chem. Phys. Lett. 590 (2013) 22-26.

44. O. Mó, M. Yáñez, I. Alkorta, and J. Elguero, Mol. Phys. 112 (2014) 592-600.

45. M. M. Montero-Campillo, M. Yáñez, A. M. Lamsabhi, and O. Mó, Chem. -Eur. J. 20 (2014) 5309-5316.

46. J. G. Hill and X. Hu, Chem.-Eur. J. 19 (2013) 3620-3628.

47. M. R. Scholfield, C. M. Vander Zanden, M. Carter, and P. S. Ho, Protein Sci. 22 (2013) 139-152.

48. M. P. Johansson and M. Swart, Phys. Chem. Chem. Phys. 15 (2013) 11543-11553.

49. A. Priimagi, G. Cavallo, P. Metrangolo, and G. Resnati, Acc Chem. Res. 46 (2013) 2686-2695.

50. M. Kaupp, M. Bühl, and V. G. Malkin (Eds.), Calculation of NMR and EPR Paramters, Wiley-VCH, Weinheim, 2004.

51. J. E. Del Bene In: M. Kaupp, M. Bühl and V. G. Malkin, (Eds.),
Calculation of NMR and EPR Paramters, Wiley-VCH, Weinheim, 2004

52. J. E. Del Bene, I. Alkorta, and J. Elguero, J. Phys. Chem. A 112 (2008) 7925-7929.

53. J. E. Del Bene, I. Alkorta, and J. Elguero, Chem. Phys. Lett. 508 (2011) 6-9.

54. J. E. Del Bene, I. Alkorta, and J. Elguero, J. Phys. Chem. A 114 (2010) 12958-12962.

55. I. Alkorta, G. Sánchez-Sanz, J. Elguero, and J. E. Del Bene, J. Phys. Chem. A 116 (2012) 2300-2308.

56. J. E. Del Bene, I. Alkorta, and J. Elguero, J. Phys. Chem. A 118 (2014) 3386-3392.

57. J. E. Del Bene, I. Alkorta, and J. Elguero, Chem. Phys. Lett. 538 (2012) 5-9.

58. J. E. Del Bene, I. Alkorta, G. Sánchez-Sanz, and J. Elguero, Z. Phys. Chem. 227 (2013) 821-838. 